Florida International University FIU Digital Commons

$10-22-2015$

\title{
An Exploration of the Reasons and Purposes of Non-Japanese Undergraduate Students for Taking a Beginners' Japanese Language Course
}

Asuka H. Mashav

Florida International University, Mashava@fiu.edu

DOI: $10.25148 /$ etd.FIDC000202

Follow this and additional works at: https://digitalcommons.fiu.edu/etd

Part of the Bilingual, Multilingual, and Multicultural Education Commons, Curriculum and Instruction Commons, Educational Administration and Supervision Commons, $\underline{\text { Higher Education }}$ Commons, and the International and Comparative Education Commons

\section{Recommended Citation}

Mashav, Asuka H., "An Exploration of the Reasons and Purposes of Non-Japanese Undergraduate Students for Taking a Beginners' Japanese Language Course" (2015). FIU Electronic Theses and Dissertations. 2305.

https://digitalcommons.fiu.edu/etd/2305 


\section{FLORIDA INTERNATIONAL UNIVERSITY}

Miami, Florida

\section{AN EXPLORATION OF THE REASONS AND PURPOSES OF NON-JAPANESE UNDERGRADUATE STUDENTS FOR TAKING \\ A BEGINNERS’ JAPANESE LANGUAGE COURSE}

A dissertation submitted in partial fulfillment of the

requirements for the degree of

DOCTOR OF EDUCATION

in

CURRICULUM AND INSTRUCTION

by

Asuka Haraguchi Mashav 
To: $\quad$ Dean Delia C. Garcia

College of Education

This dissertation, written by Asuka Haraguchi Mashav, and entitled An Exploration of the Reasons and Purposes of Non-Japanese Undergraduate Students for Taking a Beginners' Japanese Language Course, having been approved in respect to style and intellectual content, is referred to you for judgment.

We have read this dissertation and recommend that it be approved.

Linda Spears-Bunton

Sarah Mathews

Steven Heine

Hilary Landorf, Major Professor

Date of Defense: October 22, 2015

The dissertation of Asuka Haraugchi Mashav is approved.

Dean Delia C. Garcia

College of Education

Dean Lakshmi N. Reddi

University Graduate School

Florida International University, 2015 
(C) Copyright 2015 by Asuka Haraguchi Mashav

All rights reserved. 


\section{DEDICATION}

I dedicate my dissertation work to my family and friends. Special gratitude to my loving parents, Kaoru and Tomoaki Haraguchi who always support me no matter what. Special appreciation and love to my husband, Yariv Mashav, who has never left my side ever since this long journey started. Special thanks to our three little ones who joined in our lives during this journey unannounced, Yizhak, Musashi and Natan Mashav. Thank you all for your patience. I love each and all of you from the bottom of my heart. 


\section{ACKNOWLEDGMENTS}

I would never have been able to finish my dissertation without the guidance of my committee members, and support from my family. I would like to express my deepest gratitude to my advisor, Dr. Hilary Landorf as well as Dr. Steven Heine, Dr. Linda SpearsBunton, Dr. Sarah Mathews and Dr. Linda Bliss. I would also like to express my sincere thanks to Ms. Caprila Almeida, who is the Office Coordinator in College of Education. 


\author{
ABSTRACT OF THE DISSERTATION \\ AN EXPLORATION OF THE REASONS AND PURPOSES OF \\ NON-JAPANESE UNDERGRADUATE STUDENTS FOR TAKING \\ A BEGINNERS’ JAPANESE LANGUAGE COURSE \\ by
}

Asuka Haraguchi Mashav

Florida International University, 2015

Miami, Florida

Professor Hilary Landorf, Major Professor

This study took place at Florida International University (FIU), a large public research university in Miami, Florida and one of largest Hispanic serving institutions in the United States. The purpose of this study was to explore the motivations of nonJapanese undergraduate students for taking a beginners’ Japanese language course. Indepth one-hour semi-structured interviews were conducted with 12 participants before the fall semester of 2014 (Phase I) and 10 after the semester (Phase II). Two major themes emerged from the inductive analysis of the data: attraction to Japanese culture and utility of using the Japanese language. Sub-themes for attraction to Japanese culture were anime and manga, martial arts and various types of games. Sub-themes for utility of using the Japanese language were study abroad and employment which both require residing in Japan. In particular to Phase II, three other themes emerged: a sense of community, openness to others, and investment of time.

The findings were analyzed through the lens of L2 motivational-self system. L2 is a foreign language that is not the native language of the speaker. The L2 motivational self- 
system supports the idea that the images of a possible future-self as a successful learner in L2 acquisition which directs a language learner to have motivating behavior The researcher saw significant changes in participants' motivational level during qualitative comparative analysis of Phase I and II, especially for those who had and/or gained possible future L2 ideal-self during L2 learning experience.

The findings might be used by policy makers or curriculum developers for Japanese language education to refine, enhance or strengthen the competency-goals for Japanese instructions. Moreover, the findings suggested that by creating a personally relevant and inspiring vision of possible-future ideal L2 self, the students will be inherently motivated, which then allows the instructors to be more productive and effective in their teaching. 


\section{TABLE OF CONTENTS}

CHAPTER

PAGE

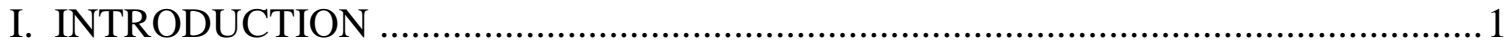

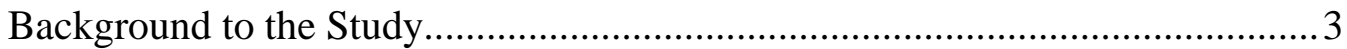

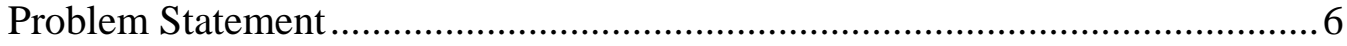

Purpose of the Study ......................................................................................

Research Question ......................................................................................

Conceptual Framework..................................................................................

Significance of the Study ................................................................................

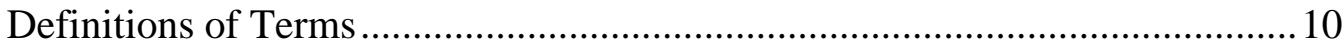

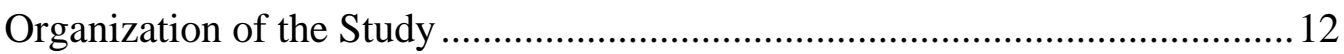

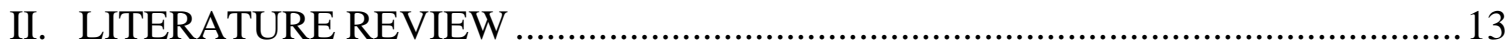

Development of L2 Motivation Theory ……………………...........................13

L2 Motivational Self System ....................................................................

Current Trends in the Study of L2 Motivation ..................................................21

Foreign Languages Education and Trends in U.S. Higher Education.................24

Reasons and Purposes of Learning Japanese Overseas .......................................28

Japanese-Language Education and Issues in the United States...........................30

New Movements for Japanese Language Education in the United States..........36

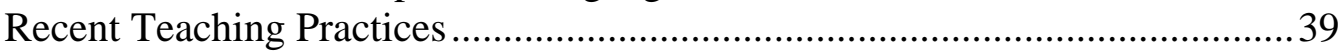

Japanese Programs in Miami-Dade County ..........................................................40

Japanese Program at FIU .......................................................................... 41

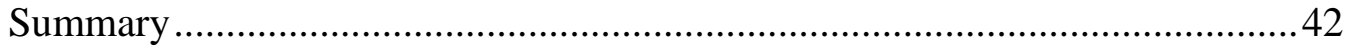

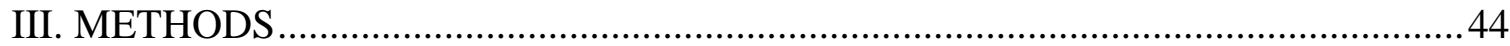

Research Question ........................................................................................ 44

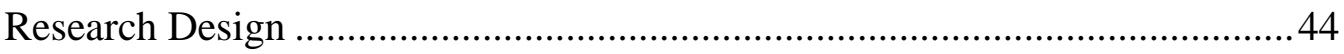

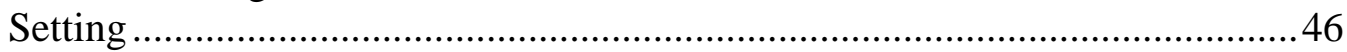

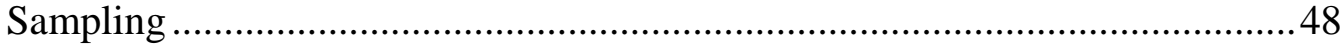

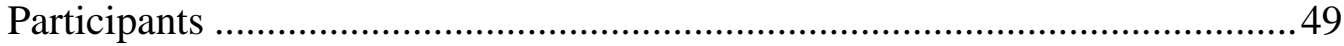

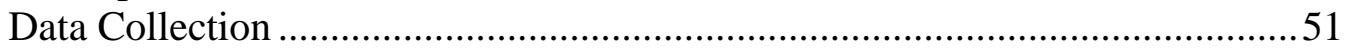

Data Analysis Procedures ................................................................................54

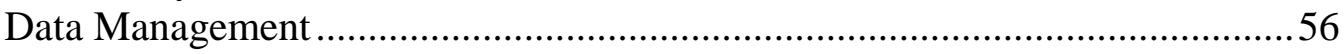

Delimitation of the Study ..............................................................................56

Role of the Researcher..................................................................................57

Researcher's Subjectivity …………………………….................................59

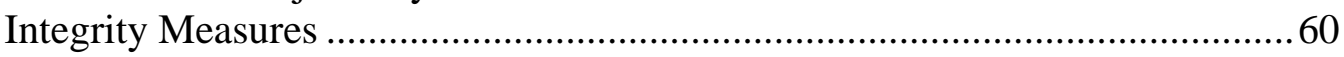

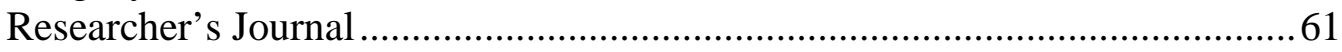

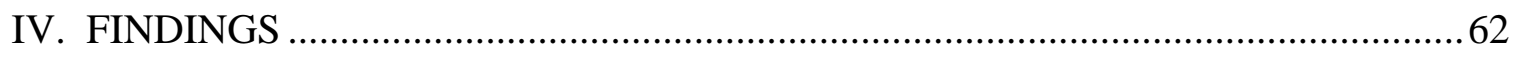

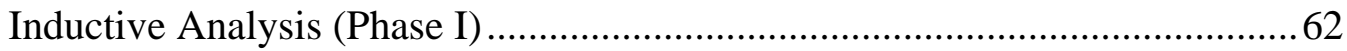

Inductive Analysis (Phase II)......................................................................... 78

Comparative Inductive Analysis (Phase I and II)............................................... 85

Three Emergent Themes (Phase II) .....................................................................91

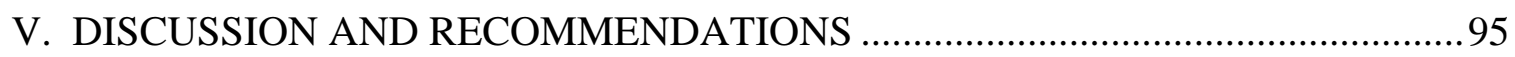


Response to Research Question ...................................................................95

Reflections through L2 motivational self-system ..........................................98

Recommendations for Future Research......................................................... 106

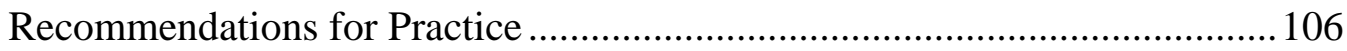

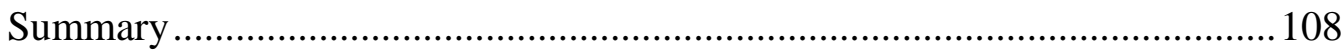

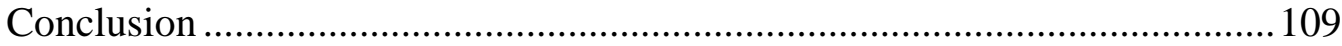

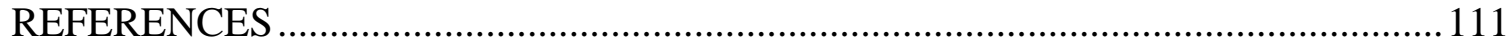

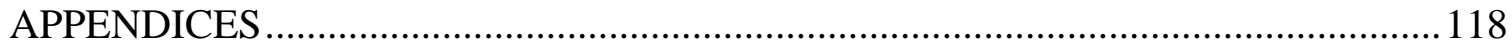

VITA 


\section{CHAPTER I \\ INTRODUCTION}

Why do university students want to learn a foreign language? How do they come to a decision on which language to study? The answers may depend on where they reside or on their family background. Perhaps the decision is made solely based on the degree requirements of their university or it may be influenced by the student's personal or professional goals. Current political and socioeconomic trends may influence their decision.

Whatever the reasons, it is well-established in education research that motivation is a crucial factor in both a student's ability to create a learning environment and in determining the outcomes of learning. In the field of second/foreign language (referred to as L2), motivation is identified as both the driving force and a key factor in determining the rate and success of L2 acquisition (Dörnyei, 2001; Gardner, 2001; Oxford \& Shearin, 1996).

Motivation has variety of definitions that describe certain terms or ideals which can also be a driving force in the pursuit of those ideals. This driving force gives purpose or direction to human behaviors. If you don't have those behaviors, action will not occur (Psychology Dictionary, 2014). Reason is "a justification of an action." Purpose is "the reason something exists or some act is undertaken" (Psychology Dictionary, 2014). These terms can be ambiguous and are sometimes used interchangeably depending on the context. For this study it is assumed that motivation is rooted in both reasons and purposes and that a reason justifies a purpose that is derived from 1 or more 
motivations. It also assumed that a reason refers to a short-time action and a purpose usually applies to a longer-term goal or series of actions.

This study explored the reasons and purposes for non-Japanese undergraduate students taking beginners’ Japanese language courses at Florida International University (FIU) by focusing on the importance of motivation for successful L2 learning. Global trends in language acquisition reveal that the popularity of Japanese language has outpaced that of both Chinese and Korean combined overall (The Japan Foundation, 2012; Ruch, 2011), and FIU is no exception. The Japanese program at FIU has experienced steady growth over the last decade. The study of other Asian languages is gaining popularity in the U.S. (Furman, Goldberg \& Lusin, 2010) and this is also reflected at FIU. There is an increase in student enrollments there for both Arabic and Chinese languages. Two sections of Korean language courses were offered for the first time in fall, 2015. Investigation of students' reasons and purposes for studying the Japanese language at FIU today may help instructors to develop curriculum and provide instruction that adequately reflects and builds upon the students' reasons and purposes for taking the course. The outcome of the research may also help to facilitate decisionmaking for administrators regarding future developments and direction of the Japanese program at FIU.

This chapter starts with the background to the study including subsections on motivation, language study in the United States, and the study of Japanese language in the United States. These sections are followed by sections describing the problem statement, the purpose of the study, the research question, the conceptual framework, the significance of the study, the definitions of terms, and the organization of the study. 


\section{Background to the Study}

The background to this study centered on three distinct areas of scholarship. These were the use of the term "motivation”, the recent trends in language study in institutions of higher education throughout the United States, and the extant study of motivation as it pertains to the Japanese language. The setting of the study, FIU, is introduced. These topics are expounded upon in later chapters.

\section{Motivation}

The term motivation is one that is wrought with controversy due to difficulty in defining the term, and as such no conclusive definition of the word exists. For the purposes of this study, Gardner and Lambert’s (1972) definition of motivation in the context of L2 acquisition will be used as the foundational understanding of motivation, while the definition provided by Bakar, Sulaiman and Rafaai (2010) will be used as an expansion. Gardner refers to L2 motivation as “...the extent to which [an] individual works or strives to learn [a] language because of a desire to do so and the satisfaction experienced in this activity” (1985, p.10). According to Bakar et al. (2010), L2 motivation "consist[s] of various elements and formats in language learning such as interest, relevance, expectancy of success or failure, belief in forthcoming rewards, decision to be involved, persistence, high activity level” (p.72). These elements provide a wide scope in understanding motivation, allowing us to consider the motivation to learn as a complex mechanism, and one that is created by the interrelationship between the learner's state of mind, their background, beliefs, and environment. If, for instance, we examine the elements of a decision to be involved in language and culture from Bakar et al.'s (2010) characterization of the term motivation in the context of a Japanese language 
learner, we may find a student who starts their day by waking up to an alarm that blares out J-pop (Japanese Pop music), watching a live stream of NHK (Nippon Hōsō Kyōkai, official English name: Japan Broadcasting Corporation) television network while they have miso soup paired with fish and rice for breakfast, and read a copy of the popular weekly magazine Shōnen Jump on the way to school.

\section{Language Study in the United States}

According to a survey study "Enrollments in Languages Other Than English in United States Institutions of Higher Education, Fall 2009” conducted by the Modern Language Association (2010), overall interest in foreign language study in higher education in the United States has been steadily increasing. This study is a comprehensive report of enrollment figures in over 200 languages taught in U.S. colleges and universities and is conducted on a regular basis. A comparison to a similar study conducted in 2006, shows that interest appears to be growing in languages such as Arabic, Chinese, and Korean. Enrollment size increased throughout the United States for Japanese language study which is ranked sixth in popularity after Spanish, French, German, American Sign Language (ASL), and Italian (Furman, Goldberg \& Lusin, 2010).

The popularity of these languages reflects the extent to which the nations where they are spoken have an impact on the United States, be it economic, politics, security concerns, culture or simply a trend. For example, the fastest growing foreign language taught in U.S. colleges and universities is Arabic, reflecting a shift of interest to current issues in the Middle East, such as terrorism (Gorden, 2010). China's growing economy is an influential factor in the increased number of students in Chinese language courses, not 
only at the university level but also in secondary education institutions (Dobuzinskis, 2011). The growing international popularity of Korean culture as expressed through entertainment, food, and language is a well-recognized trend encapsulated in the term Hallyu (한루), or the Korean wave. According to the Korea Culture and Information Service (Jae-Un, 2012), the fame or notoriety of the South Korean rapper Psy of “Gangnam Style” fame has influenced the international rise of enrollment in Korean language classes. It appears that there may be a correlation between the languages that individuals choose to study and current socioeconomic, political, social, and cultural trends throughout the globe.

\section{Study of Japanese Language in the United States}

Until the 1970s, the main reasons and purposes of students learning the Japanese language in the United States appeared to be linked to their desire to learn about the country of Japan. This changed in the 1980s, when the preeminence of the Japanese economy became one of the primary motivational factors for students studying the Japanese language (The Japan Foundation, 2006). What sets the current period of interest in Japanese culture and language apart from the past is that Japan is no longer going through the same ascendant economic growth that it had experienced in the 1980s.

The Japan Foundation has been conducting a worldwide survey on Japanese language education every three years since 2003. In the most recent survey completed in 2012 the most frequently cited reasons and purposes behind studying Japanese were (a) interest in Japanese language (62.2\%), (b) communication in Japanese (55.5\%) and (c) interest in manga, anime, J-pop, etc. (54.0\%). No study has been done focusing exclusively on learners in the United States; $82.1 \%$ of survey respondents were in South 
East and East Asia (The Japan Foundation, 2012). Survey questionnaires for this study were answered by institutions and not the learners themselves.

The present study was conducted at FIU, the fifth largest public university in the nation in terms of enrollment. FIU serves a largely Hispanic student body of over 54,000 and offers more than 200 bachelors, masters, and doctoral programs in a wide variety of fields (Florida International University, 2014). In little over a decade, the Japanese program at FIU has increased from an enrollment of around 30 to over 250 per semester. This growth has been continuous despite factors such as (a) the great geographic distance between Japan and Miami; (b) the small Japanese population in Miami; (c) Miami’s predominantly Hispanic population; (d) Japan’s experience of a devastating earthquake and its aftermath in March, 2011; and, (e) the recent closing down of several Japanese programs in K-12 in Miami-Dade and Broward County public schools. Understanding the reasons and purposes for Japanese language study by non-Japanese undergraduate students at FIU has become a topic of increasing interest to the administrators and teacher of the Japanese program at FIU.

\section{Problem Statement}

Although research into L2 motivation may be flourishing as Dörnyei (2001) claims, specific research on the motivation of the increasing numbers of non-Japanese undergraduate students learning the Japanese language in the United States is scarce. Existing studies often identify students’ L2 motivation by quantifying a singular force without considering related factors such as course requirement, school curriculum, and the context and background of the research site. These could be important motivational factors, for example, of a student taking Japanese language courses in a place with a rich 
Japanese cultural tradition as compared with a student learning the language to complete a requirement for their major at a university in North Dakota where there is little Japanese influence or presence. It is important to consider these types of factors in conjunction with the specifics of learning environments, in order to paint a more complete picture of the students themselves. Therefore, it is important to conduct a qualitative research study with direct input from the learners.

\section{Purpose of the Study}

The purpose of the study was to examine the reasons and purposes behind the decisions of non-Japanese undergraduate students to enroll in a beginners’ Japanese language course at Florida International University.

\section{Research Question}

What are the reasons and purposes for non-Japanese undergraduate students in taking a beginners’ Japanese language course at Florida International University?

\section{Conceptual Framework}

The conceptual framework used in this study was derived from a L2 motivational self-system (Dörnyei, 2005, 2009). The L2 motivational self-system considers that motivation is an umbrella term that encompasses reasons and purposes. It was developed as an advancement of previous theories in $\mathrm{L} 2$ research and on the basis of the psychological theory of self-discrepancy (Higgins, 1987), which assumes that human beings are motivated to reduce the gap between their actual self and ideal self. This model was also developed from the notions of "possible-selves." Possible-selves is a type of self- knowledge that pertains to how individuals think about their potential for their future. 
The L2 motivational self-system consists of three elements: (a) the ideal L2 self, which is based on the individual's aspirations and goals as a language learner, (b) the ought-to L2 self, which is a product of the individual's perceived obligations and responsibilities as a language learner, and (c) the L2 learning experience, which consists of more situated, executive motives related to the immediate learning environment (Dörnyei, 2009, p.29). This theoretical framework was suitable for the research study. First, the L2 motivational self-system specifically deals with motivation for acquiring L2 skills, not just motivation in general. Secondly, the L2 motivational self-system provides broad range of considerations when it comes to the person's motivation for L2 learning including the past, present and future.

Interview questions for individual in-depth interviews were constructed based on the L2 motivational self-system model. The questions reflected each dimension of the L2 motivational self-system and were asked in two phases:

Phase I (At the beginning of the semester)

1. Aspirations and goals

2. Perceived obligations and responsibilities

3. Previous L2 learning perception in general

Phase II (At the end of the semester)

1. Aspirations and goals

2. Perceived obligations and responsibilities

3. Reflections on L2 Japanese learning experience at FIU 


\section{Significance of the Study}

Using the three dimensions and the concept of the L2 motivational self-system, an exploration of reasons and purposes of non-Japanese undergraduate students for studying Japanese language at FIU gave the researcher in-depth descriptions and understandings of why they take a beginners' Japanese language course at FIU. This framework also provided the research to explore the dynamic forces of the motivational and attitudinal changes in learners after the experience of learning the language for a semester at FIU.

As previously stated, motivation is crucial to the student's learning and experiential outcomes. By understanding the L2 motivations it is possible to create relevant curriculum and content for the student. It is also important so that the educators involved, both instructors and administrators, are aligned on the same goals and outcomes. The outcome of the research could help to facilitate decision-making for administrators regarding the future of the FIU Japanese program, as well as the development of curriculum and instruction methods. Instructors may also be able to become more productive and effective in their teaching by creating a personally relevant and inspiring vision of a possible-future L2 self so that the student will be inherently motivated using possible future-self.

Beyond the scope of FIU, this research has potential significance in the field of teaching and learning in general. First, exploring the reasons and purposes for choosing a course can lead to a clarification of the students' vision of their future possible selves. Second, this study will contribute to teachers' productivity by utilizing their students' future possible-selves' vision in their teaching. Focusing on this vision can decrease 
students' apathy and create an exciting relationship between the students and the subject of learning. As Boyatzis and Akrivou (2006) stated:

Humans are driven by their imagination and their ability to see images of the desired future. Leaders, poets, writers, composers, artists, dreamers, athletes have been able to be inspired, stay inspired and inspire others through such images. These images, once shared, have the power to become a force, and in that sense an inspiration for social development and growth, for intentional change at many levels of social organization, not just for the individual. (p. 633)

\section{Definitions of Terms}

Anime. An abbreviated word for animation used in Japan; a style of animated cartoon with roots in Japan often associated with colorful images and action-oriented storylines (Merriam-Webster, 2015).

Hikikomori. Defined by the Japanese Ministry of Health, Labor and Welfare (2010) as an individual who refuses to leave their parent's home and isolates themselves from society and family members by staying in the confines of a single room for a period exceeding six months.

J-pop. Japanese pop music typically characterized by youthful girl bands, boy bands, or solo artists simultaneously performing vocal and dance routines in elaborate productions. (Music Genre’s List, 2010-2015).

L2. Second Language/Foreign Language (Glossary of TEFL Acronyms, 20022012).

Manga. A style of graphic novel or comic book popular in Japan (MerriamWebster, 2015). 
Motivation to learn a second language. Defined by Gardner (1985) as “...the extent to which [an] individual works or strives to learn the language because of a desire to do so and the satisfaction experienced in this activity” (p.10).

Motivational factors. Various elements and means involved in language learning such as “interest, relevance, expectancy of success or failure, belief in forthcoming rewards, decision to be involved, persistence, [and] high activity level” (Bakar, Sulaiman, \& Rafaai, 2010, p.72).

Otaku. A term used to refer to people with obsessive interests, commonly in anime, manga, and/or other representations of a fictitious or fantasy world. It derives from a combination of the Japanese honorific "O” and “Taku”, which means home. It carries multiple meanings, but is popularly recognized as having a negative connotation. (Dictionary.com, 2015).

Purpose. “The reason something exists or some act is undertaken” (Psychology Dictionary, 2014).

Reason. "A justification of an action" (Psychology Dictionary, 2014).

Sempai and Kohai. Sempai refers to one that is older or superior in skill. while, kohai means one who comes after, or simply juniors (Tsunagu Japan, 2014).

Shōnen Jump. A weekly manga anthology for young men and boys published in Japan by Shueisha under the Jump line of magazines. It is Japan’s best-selling manga magazine, as well as one of the longest-running. Manga series within the magazine target young male readers and tend to consist of a large number of action scenes and a fair amount of comedy (Free Dictionary, 2003-2015). 
Sokagakkai. A relatively new religious organization in Japan associated with Nichiren Buddhism (Merriam-Webster, 2015).

\section{Organization of the Study}

The study is divided into the following chapters. Chapter 2 consists of two sections, the development of theories of motivation in L2 and topics in foreign language study in US higher education. Chapter 3 describes the methods used in the design and conduct of the study and all aspects of the research including research design, data collection, data analysis, and the role of the researcher. Chapter 4 presents the data analysis and findings. Chapter 5 presents a response to the research question, reflections on findings through the lens of L2 motivational self-system, recommendations for future research and practice, a summary, and the conclusion. 


\section{CHAPTER II}

\section{LITERATURE REVIEW}

This review of the literature is comprised of two sections. The first section covers theories on L2 motivation in general, the L2 motivational self-system that serves as a conceptual framework for this study, and current trends in the study of L2 motivation. The second section investigates foreign language education generally and the trends in U.S. higher education. This is followed by a discussion of the reasons and purposes of learning Japanese language outside of Japan, and the subject of Japanese language education and related issues in the United States today including new movements of Japanese language education in United States. The status of Japanese programs in MiamiDade County in South Florida and of the Japanese Program at FIU was examined so as to have local context. The chapter concludes with a summary.

\section{Development of L2 Motivation Theory}

It is common to find only a limited representation of motivation in L2 literature, because the term motivation in the context of language acquisition has been difficult to explain, and as such there has been little consensus among researchers as to its actual definition (Dörnyei \& Ushioda, 2013). The authors explained the complexity of motivation in their recent book "Teaching and researching: Motivation" and stated that "Researchers are inevitably selective in their focus since it seems impossible to capture the whole picture” (p.4). They presented their most important dimensions of motivation as concerning directions and magnitude of human behavior as:

- the choice of particular action,

- the persistence with it, 
- the effort expended on it,

In other words, motivation is responsible for:

- why people decide to do something,

- how long they are willing to sustain the activity,

- how hard they are going to pursue it. (p.4)

Gardner (1985) has presented motivation in the L2 context as “...the extent to which an individual works or strives to learn the language because of a desire to do so and the satisfaction experienced in this activity.” (p. 10) Further, motivation consists of various elements in language learning such as “interest, relevance, expectancy of success or failure, belief in forthcoming rewards, decision to be involved, persistence, high activity level” (Bakar et al., 2010, p.72). The researcher used Gardner’s (1985) definition of motivation as foundation of the term but also included Bakar's definition to look at motivation especially from the beginning of decision-making.

Motivation is essential in L2 acquisition because language learning starts from very basic premises. Motivation determines "the choice of language to be learned, the kinds of activities that learners are more inclined to engage in, the types and extent of proficiency that learners expect to attain, the degree of external intervention needed to regulate learning and the extent of engagement in the long run" (Bakar et al., 2010, p. 72). Dörnyei (1998) stated that with regard to the importance of motivation in L2 acquisition:

Without sufficient motivation, even individuals with the most remarkable abilities cannot accomplish long-term goals, and neither are appropriate curricula and good teaching enough on their own to ensure student achievement. On the other 
hand, high motivation can make up for considerable deficiencies both in one’s language aptitude and learning conditions. (p. 117)

Considering the importance of motivation, it comes as no surprise that researchers have long been investigating and creating theories of motivation. Dörnyei (2005) has provided us with a framework that describes the last 50 years in the development of these theories. He divides the research into three periods: (1) The Social Psychology Period (1959 -1990), (2) The Cognitive-Situated Period (1990s), and (3) New Approaches: The Process-Oriented Period (after 2000).

The Social Psychology Period began when Gardner and Lambert $(1959,1972)$ developed their key framework for the study of motivation in L2 acquisition. Based on the Socio-Educational model, it was founded on a dichotomy between what they referred to as integrative and instrumental motivations. Integrative motivation referred to the learner's positive attitudes towards the target language group, as well as their desire to integrate into the target language community (Crookes \& Schmidt, 1991). Instrumental motivation is "the desire to obtain something practical or concrete from the study of a second language... [It] underlines the goal to gain some social or economic reward through L2 achievement” (Hudson, 2000). However, a growing amount of research has pointed out that it may be practically impossible to distinguish motivation between the two types in the manner prescribed by Gardner’s model (Narayanan, 2006). Gardner himself has admitted that this categorization is restrictive, conceding that the sheer complexity of reasons for an individual to study another language demands a broader categorization than only two classifications allow (Moiinvaziri, 2008). There are in fact other examples of motivations to study another language. Ely (1986), in a study of 
freshman Spanish students in the United States discovered requirement to be a motivational orientation. Skehan (1991) found in his study that "individual differences" was a more important motivational orientation than the instrumental/integrative distinction. Dörnyei’s (1990) study of adult Hungarian English learners raised a point of distinction between Foreign Language Learning and Second Language Learning that may influence motivational orientation. The distinction between the two learning environments is that a second language is a language that is learned after one has already learned their first language, and a foreign language is a language that is from a country other than one's native language. Also, second language learning takes place in the country where the language is spoken while foreign language learning is foreign in the country where the language is being taught.

The cases above demonstrate the constraints inherent to Gardner's model, and as such researchers began to call for the need to develop and investigate other motivational orientations in the study of L2 motivation (Crookes \& Schmidt, 1991; Dörnyei, 1994; Oxford \& Shearin, 1994) and emphasized the need to incorporate theoretical approaches other than traditional ones (Gardner \& Tremblay, 1994).

During the following Cognitive-Situated Period, new methodological approaches were explored from the perspective of cognitive theories in educational psychology. Among others, two new concepts were Ryan and Deci's “Self-Determination Approach" (Ryan \& Deci, 2000) and Richard Clément’s model of "Linguistic Self Confidence” (Clément, Dörnyei, \& Noels, 1994). Self-Determination Approach “...begins with the assumption that people are active organisms, with evolved tendencies toward growing, mastering ambient challenges, and integrating new experiences into a coherent sense 
of self.” (“Self-Determination Theory,” 2015). This concept of self-determination is with the intrinsic nature of human beings. Self-Determination Theory focuses "on how social and cultural factors facilitate or undermine people's sense of volition and initiative, in addition to their well-being and the quality of their performance" ("Self-Determination Theory,” 2015). Linguistic Self Confidence is the first model that introduced linguistic self-confidence as a motivational factor in L2 learning (Clement et al., 1994). The authors originally argued the importance that an individual's attitude and effort to learn and speak to L2 members would result in L2 success and that self-confidence is the most significant determining factor of motivation in L2 learning process leading to successful learning.

The third period, the Process-Oriented Period, in which the current study takes place, has thus far consisted of the emergence of research interest in motivational change, as initiated by the work of Dörnyei, Ushioda, and their colleagues in Europe. Dörnyei (2009) has proposed the “L2 Motivational Self System,” a framework which involves the concept of integration in a much deeper sense than has been allowed in the past. He suggested that examining the relationships between learners' motivation and their learning behaviors, including their situated identity and self-perceptions, links L2 motivation research more closely with processes of L2 acquisition. In particular, he links motivation with the idea of "possible-selves," a concept which represents what a student imagines their future-self to be (Dörnyei, 2009).

\section{L2 Motivational Self System}

As discussed above, Gardner and Lambert’s (1959) integrative orientation has been a dominant concept in the L2 motivational field for the past 50 years. They claim that, a learner's willingness to become a member of L2 community integration is the 
most important motivational factor. However, Dörnyei (2009) pointed out that the role and status of English in a multicultural context today necessarily renders the learner’s target of integration unclear. Suzuki (2011) also questioned Gardner and Lambert's theory because of its inability to generalize the theory especially considering English as Foreign Language (EFL) learners who have few opportunities to directly communicate with an L2 community, such as English language learners in Japan. To fill the gap between theory and actual learning context, this new framework of the L2 motivational self-system was proposed by Dörnyei (2009) which consists of the following three dimensions.

1. Ideal L2 self

a. The ideal L2 self is based on the individual's aspirations and goals as a language learner.

b. The ideal L2 self refers to "the representation of the attributes that one would ideally like to possess (i.e. representation of hopes, aspirations, or wishes)” (Dörnyei, 2009, p.13).

c. The ideal L2 self is “a powerful motivator to learn the L2 because of the desire to reduce the discrepancy between our actual and ideal selves” (Dörnyei, 2009, p.29).

2. Ought-to L2 self

a. The ought L2 self refers to "the representation of attributes that one believes one ought to possess (i.e. representation of someone else’s sense of duties, obligations or moral responsibilities) and which 
therefore may bear little resemblance to one's own desires or wishes.” (Dörnyei, 2009, p.13).

b. The ought L2 self concerns "the attributes that one believes one ought to possess to meet expectations and to avoid possible negative outcomes. This dimension corresponds to the more extrinsic (i.e. less internalized) types of instrumental motives” (Dörnyei, 2009, p.13).

\section{L2 learning experience}

a. L2 learning experience concerns situated, “executive” motives related to the immediate learning environment and experience (e.g. the impact of the teacher, the curriculum, the peer group, the experience of success). This component is "conceptualised at a different level from the two self-guides and future research will hopefully elaborate on the self-aspects of this bottom-up process” (Dörnyei, 2009, p.29).

The key component of the L2 motivational self-system consists of an idea of “possible selves.” This idea was first presented by Markeus and Nurius (1986). Their theory described as to how the self regulates behavior by setting goals and expectations. Possible selves are the ideal selves that we would very much like to become. They are also the "selves we could become, and the selves we are afraid of becoming” (Markus \& Nurius, 1986, p.954). Dörnyei (2009) asserts that the images of a possible future-self are powerful tool for envisioning oneself as a successful learner in L2 acquisition, and such vision directs a language learner to have motivating behavior.

The first two dimensions, the ideal-self and the ought-to self-function as future self-guides. The main differences between the two is that the ideal self provides a 
promotion focus (e.g., advancement, growth, accomplishment) involving internallydriven motivation and self-regulation considering L2 mastery as a long-range goal. On the other hand, ought-to self deals with a prevention focus (e.g., failing exams, disappointing one’s parents, safety, security) and aims to avoid possible negative outcomes through more externally-regulated duties, obligations, or necessities. Furthermore, the ideal-self is reflected by one's own future self-images, whereas the ought-to self represents the hoped for end-states others have for the individual (Higgins, 1987).

Possible selves cannot be solely shaped within the individual without reference to social/cultural forces. L2 identities need to be understood within the particular learning context under investigation. Taking this point as a consideration and utilizing L2 motivational self-system, Kim (2012) compared Dörnyei’s (2009) motivational selfsystem with Gardner’s (1985) socio-educational model in attempt to seek paradigmatic reconstruction of conventional EFL/ESL motivation due to changing status and the role of English language. He investigated Korean students' English learning motivation from different grades in different schools. The results of the cross-grade survey indicated that Dörnyei’s L2 motivational self-system was a better predictor than Gardner's socioeducational model in terms of the explanatory power for students' English proficiency. Students' ideal L2 and ought-to L2 selves explained better than Gardner's integrativeness concept and two types of instrumentality such as promotion and prevention-based (Kim, 2012). Similar results were found in Chen's (2012) interview study of Taiwanese EFL learners. Based on his interview study, L2 motivational self-system applied its explanatory power in the Taiwanese EFL context and the ideal L2 self and the ought-to 
L2 self were helpful in informing the analysis of student motivation. The ideal L2 selfillustrated with empirical evidence corresponds to Dörnyei’s approach towards L2 self. Suzuki (2011) compared ideal L2 selves among Japanese English learners at different motivational levels based on the idea that the L2 learner's desirable self-image using the target language has a great impact on L2 learning motivation. By comparing and analyzing these two images, influential factors in developing a positive ideal L2 self, as well as authentic applications for better motivating learners were found in her research study.

\section{Current Trends in the Study of L2 Motivation}

Traditionally, it has been assumed that L2 learners bring their own motivation to every learning condition, and that this motivation is consistent over time. Referred to as “trait motivation," this concept has been central to the study of motivation in the context of L2 acquisition. However, in connection with the perspective of viewing motivation in relation to language learning behaviors, L2 researchers have also started to look at motivation as a "state manner" which views motivation as a more changeable element.

There is a move toward a more situated approach to L2 motivation, highlighting dynamic and changing characteristics of L2 learning motivation (Dörnyei, 2002; Dörnyei \& Ottó, 1998) unlike Gardner’s views of motivation.

Another major trend in the study of L2 motivation is the attempt to link L2 motivation research with theories in other fields such as the different areas of psychology. The emphasis here is on interdisciplinary work. Since existing theories have been based primarily upon research in second language (particularly Canada and Europe) or bilingual settings with groups of learners from primarily Western countries, the change in focus to 
more diverse group of foreign language contexts is meaningful. Linking motivation research with theories in the fields such as psychology to studying language learning in non-Western countries allow exploring the validity and applicability of existing theories under a variety of circumstances. For instance, Schmidt and Savage (1992) found in their study on EFL motivation that, among Thai people, the level of challenge played a lesser role in motivation than it does elsewhere, and concluded that this was due to cultural differences. Similarly, Bakar et al., (2010) demonstrated in her dissertation that religious motivations have emerged as a new statistical sub-dimension of motivational orientation for Muslim learners of Arabic. Johnson and Johnson (2010) explored the motivations of Japanese engineering EFL students and found past language learning trauma and ongoing demotivation in this particular profile, calling for the uncovering of unexplored contexts in research and the use of a combination of qualitative, quantitative, and longitudinal instruments.

Lastly, the introduction and application of a new and diverse set of methodologies is widely considered to be a new trend in the study of L2 motivation. Today, more and more researchers are assessing L2 motivation by analyzing data from surveys, diaries, observation, in-depth interviews, essays, performance output, engagement time, conversational analysis, persistence, case studies, and other innovative methods. In the past, L2 motivational studies showed exclusive reliance on standardized questionnaire instruments which were usually one-shot correlational studies such as Gardner's (1985) Attitude/Motivation Test Battery (AMTB). However, the number of longitudinal studies exploring L2 motivation has increased, resulting in more discoveries about the motivational changes over time and about the effects of motivation on L2 learning 
outcomes. For example, Koizumi and Matsuo (1993) examined over 1 year attitudinal and motivational changes of 296 Japanese 7th-grade students (150 boys and 146 girls) learning English. The study mainly attempted to explain the phenomenon that they found which was that the participants' motivation dropped after the initial stage of the learning process. For example, students with initially high English ability performed better and showed more positive attitudes and motivation than those with initially low ability. Also, girls had a lower expectancy of their own performance than boys in the goal-setting area. However, girls had higher scores than boys in most attitudinal and motivational variable. Dörnyei, and Csizér (2002) investigated how the significant sociocultural changes that took place in Hungary in the 1990s affected school children's language-related attitudes and language learning motivation. Five target languages were English, German, French, Italian, and Russian. The analyses are based on survey data collected from 8,593 13/14-year-old students on two occasions in 1993 and 1999. They explored the changes that characterized the learners' motivation between the two phases of the survey. Findings showed that the learners' general language learning commitment showed a significant decline, except for English. The researchers interpreted the findings as a reflection of what they call a 'language globalization’ process; that English language was a global language, while German, French, Italian and Russian languages showed increasingly different motivational patterns.

Other than the recent trends in research on L2 motivation, Oxford and Shearin (1994) mentioned four items that must be considered in the L2 motivation research: 
1. Absence of a Consensus on a Definition of L2 Learning Motivation

2. Confusion surrounding motivation in the second vs. foreign language settings

3. L2 research's omission of some key motivational and developmental theories taken from areas of psychology

4. Teachers' lack of knowledge about their students' reasons for learning a language

\section{Foreign Languages Education and Trends in U.S. Higher Education}

Since 1958, the Modern Language Association (MLA) has been conducting regular surveys and publishing reports of the analysis of the study of languages other than English at U.S. colleges and universities. This is the longest running and most comprehensive analysis in the field., The most recent report in Fall 2009, and the twentysecond survey in the series, counted undergraduate and graduate course enrollments in languages other than English at 2,514 colleges and universities in the United States. The institutions covered in the survey account for $99 \%$ of all higher education institutions offering languages in the United States. Approximately one third of the responses came from two-year colleges; the rest came from four-year institutions. It is important to note that the enrollment number represents the number of seats taken in a course, not the numbers of students, and as such a student who enrolls in more than one language course for the same language is counted only once. However, these statistics can serve as an important indicator for the trends in language studies in U.S. higher education.

Overall, the report finds that the enrollment in languages other than English at U.S. institutions of higher education has continued to grow over the past decade and is 
diversifying to include an increasingly broad range of language studies. As a result, course enrollments in languages other than English reached a new high in 2009. The most studied languages on college campuses in fall 2009 and their statistical comparison to the next nearest study (2006) are shown in Table 1.

Table 1.

Students Enrolled in Foreign Language Courses in Higher Education Institutions in USA

\begin{tabular}{lcc} 
Language & Number of Enrolled Students & Increase from 2006 \\
\hline Spanish & 864,986 & $+5.1 \%$ \\
French & 216,419 & $+4.8 \%$ \\
German & 96,349 & $+2.2 \%$ \\
ASL & 91,763 & $+16.4 \%$ \\
Italian & 80,752 & $+3.0 \%$ \\
Japanese & 60,976 & $+18.2 \%$ \\
Chinese & 73,434 & $10.3 \%$ \\
Arabic & 35,083 & $+46.3 \%$ \\
Latin & 32,606 & $+1.3 \%$ \\
Russian & 26,883 & $+8.2 \%$ \\
\hline
\end{tabular}

There were a number of key findings in the Fall 2009 report which compared the results to previous reports in previous years. Spanish enrollments showed continued growth, but at a more modest rate of 5.1\% in 2009 as compared with $10.3 \%$ in 2006 and 13.7\% between 1998 and 2002. Spanish, French, and German are still the three most studied languages and gained in enrollments in higher education institutions in U.S, representing more than $70 \%$ of language enrollments. The enrollments in these 3 languages are increasing, but at a slower pace. In 2009, French, German, and Italian posted modest gains of $4.8 \%, 2.2 \%$, and $3.0 \%$, respectively. 
The enrollment in language courses other than English is growing and diversifying at U.S. colleges and universities, especially the study of Arabic, Korean, Chinese, and American Sign Language (ASL). The study of Arabic registered the largest percentage growth at U.S. colleges and universities since the previous MLA report in 2006. Enrollments in Arabic language courses grew by 46.3\% between 2006 and 2009, building on an increase of $126.5 \%$ in Arabic enrollments in the previous MLA survey, the first in which the language appeared among the ten most studied at U.S. colleges and universities. Arabic is now the eighth most studied foreign language at U.S. colleges and universities, up from tenth in 2006.

ASL follows after German, which jumped to fourth in the 2006 survey and held that position in 2009. Italian, Japanese, and Chinese come next, in the same sequence they have occupied since 1998.

Overall, it appears that the trends in language enrollment could relate to significant national and global developments and current economic, political, social and cultural trends. Interpretation of the statistics offers an in-depth view of the reasons behind growth that experienced in certain languages over the past few years. For instance, increasing enrollment in Arabic programs demonstrates that there is high demand for Arabic-speakers in the Western world. While the importance of Middle Eastern politics in international affairs is growing, there remains an extreme shortage of workers in the West who are versed in the Arabic language and its culture. The U.S. government has designated Arabic as a language of strategic importance, and as such The National Strategic Language Initiative that was instituted in 2006 promotes the learning of Arabic (and other languages deemed critical) among Americans through numerous scholarships 
and supported learning opportunities (AUSA, 2010). Korean language enrollment has been growing rapidly in recent years, as people more become interested in Korean culture in response to Hallyu (한류), a Korean cultural wave that includes K-pop and K-drama. When its first branch opened in Los Angeles, Seijong Hakdang, a branch of the Korean government that both monitors and conducts Korean language learning, did not receive many non-Korean students; indeed, its initial enrollment was 75 percent KoreanAmericans. This year, however, 74 percent of its students are non-Korean. Basic-level courses are more than 90 percent non-Koreans (Jae-un, 2012). China is growing economy is an extremely influential factor that has increased the number of students who choose to study Chinese in higher education institutions, as well as those in K-12. In 2006, for example, in grades K -12 in particular, the U.S. Secretary of Education announced an award of \$12.9 million in grants to school districts in 22 states. Additionally, a continuation of approximately $\$ 10$ million was given for use by the existing Foreign Language Assistance Program (Bradshaw, 2006). The increase in the study of ASL is linked with a growing awareness that "ASL is a fully developed, autonomous, human language,” said Kristen Harmon, professor of English at Gallaudet University (Finston \& Aurigemma, 2010).

It takes a vast amount of time for native speakers of English to achieve a high level of proficiency in another language. Japanese is no exception and it is well known for the linguistic complexity of its formality levels and styles. Not only must the syntactic, lexical, and orthographic differences between English and Japanese be considered, but there are also distinct differences between spoken and written styles where age, gender, and situation-appropriateness must be taken into account. In order to be able to read 
Japanese materials written for adult native speakers, one must learn two different phonetic writing systems (kana) and approximately 2000 Chinese characters (kanji), most of which have multiple meanings and readings.

The Defense Language Institute has categorized languages into four levels of difficulty and has set the normal maximum training time for a Category IV language such as Japanese at 64 weeks, as compared to just the 26 weeks allowed for Category I languages such as Spanish, French, Italian and Portuguese (AUSA, 2010). Despite the difficulty of mastering the Japanese language, the enrollment in Japanese courses has significantly increased at all academic levels, especially during the time of Japan’s economic success in the 1980s. The number of high schools offering Japanese language rose from about 200 to over 770 between 1986 and 1991 (Jorden \& Lambert, 1991), somewhat similar to the current trend enjoyed by Chinese language instruction in the United States, also due in part to the recent growth in China's economy. Recently, Japanese language education in the United States has experienced some setbacks, since the collapse of the Japanese asset price bubble and the ensuing recession of the late 1980s. While the overall numbers of students learning Japanese language has increased worldwide, the numbers of programs and students have decreased, especially in K-12 institutions (The Japan Foundation, 2012).

\section{Reasons and Purposes of Learning Japanese Overseas}

The Japan Foundation’s report, “Japanese-Language Education Overseas,” provides insight into the general trends of Japanese language education overseas. It is important to note, however, that while the foundation conducted in-depth surveys of Japanese language learners in the years 2006, 2009, and 2012, a direct comparison cannot 
be made between the results of the 2006 survey and those that followed. This is due to the fact that the provisions of the survey changed after 2006; instead of asking respondents to select up to five items as their purpose for learning Japanese overseas as had been done in the years prior, the 2009 survey prompted respondents to select as many items as applied to them. Additionally, the surveys after 2006 have added new items to their list, such as “Learning about manga, anime, etc.”, and “Institutions policy.” According to a Japan Foundation representative, these items were added because of a worldwide trend. It is important to bring attention to these additions since the selection of "Institutions policy" will inform the reader whether studying the language was required or not. Thus, the only direct comparison can be done between 2009 and 2012. Further, the most recent report in 2012 named this particular section of the survey not just "purpose” but also "reasons", because of the added item "Learning about manga, anime, etc."

The Japan Foundation's 2012 survey indicated that the most common motivations for overseas students in studying the Japanese language were (a) interest in Japanese language (62.2\%) (b) to be able to communicate in Japanese: (55.5\%), (c)interest in popular culture such as manga, anime, J-pop,(54.0\% ), and (d) interest in Japanese history or literature (49.7\%)

Another source that can be used to gauge the motivations of people learning Japanese is the Japanese Language Proficiency Test (JLPT). The JLPT is an exam that is administered by the Japan Foundation in conjunction with the Japan Educational Exchanges and Services. Since its inception in 1984, it has been the most widely recognized measure of proficiency in the Japanese language throughout the globe. In its first year, the JLPT was administered one time in 15 countries, and serviced 
approximately 7,000 examinees. Consider this in contrast to these same items in 2012 (conducted twice in 136 countries for nearly four million examinees), and the breadth of the exam becomes very clear, indeed.

Though the JLPT test-takers in 2012 were primarily undergraduate and graduate students attending post-secondary educational institutions, working adults, secondary school students, and even primary school students were also well-represented populations. According to information obtained by the Japan Foundation (2012), motivations for taking the test varied; while 35.7 percent of respondents took the test in order to gauge their own level of Japanese, 31.2 percent believed that it would be useful to them in the workplace, and 21.6 percent found it necessary for their education, either for admissions to universities in Japan or their native country (8\%), or else to other forms of educational institutions (13.6\%).

\section{Japanese-Language Education and Issues in the United States}

The number of countries and number of institutions awarding degrees in areas such as Japanese Language, Japanese Language Education, or Japan Studies is also increasing. The number of Japanese language students in the United States has increased at institutions of higher education and in non-academic education (The Japan Foundation, 2012). Despite this fact, Yasuhiko Tosaku (2009) warned us with some concerns related to Japanese language education in the United States (a) a lack of interest from both students and administrators; (b) a lack of institutional support; (c) a lack of articulation at all levels of Japanese education; and, (d) a lack of certified Japanese teachers. 


\section{Lack of Interest in Japanese Language}

Data gathered by the Japan Foundation in its 2009 "Survey Report on Japanese Language Education Abroad” indicates that there are many challenges facing Japanese language education programs in the United States The first is a lack of interest in Japanese among potential students, which can lead to a decline in enrollment, and the eventual closure of an entire language program. In a survey report on Japanese Language abroad, Lin (2006) presented an article entitled “How to Save Your Japanese Program” that warned of the discontinuation of Japanese programs all around the United States Since then, the trend he warned about has been clearly witnessed around the country; many Japanese programs, especially in K-12, have been disappearing. The county in which this study is being held, Miami-Dade, as well as neighboring counties in Florida were no exception. Lin also warned of the gradual phasing out or the sudden elimination of one or more foreign language programs in favor of other programs available in public schools in the United States.

\section{Funding an Institutional Support}

According to the State Department, less than one percent of all American high school students study Arabic, Chinese, Farsi, Japanese, Korean, Russian or Urdu. The \$12.9 million in new grants announced in 2006, together with the continuation of funding for existing Foreign Language Assistance grants, totaled more than \$22 million (U.S. Department of Education, 2006), but Japanese was not included among the list of target languages. This directly relates to the lack of funding for Japanese education at both the governmental and institutional levels. More recently, funding for all foreign languages in the U.S. educational system has experienced severe reductions. The Department of 
Education program that gave $\$ 27$ million worth of foreign language education grants, the Foreign Language Assistance Program (FLAP), was cut from the department's budget, leaving many programs throughout the country in a scramble to find funding (Koebler, 2012). Besides FLAP, many foreign language programs are being cut by state legislatures, especially in elementary schools, where foreign language courses are often recent additions and therefore easily done away with. This general loss of funding, coupled with the U.S. government's perception of the Japanese language as having little economic or security value, creates a situation in which Japanese education is neglected by the national government, and the growth of its programs has been impacted as a result. According to a report released in April 2013 by the American Council on the Teaching of Foreign Languages (ACTFL), the number of K-12 students taking Chinese courses (a language considered economically valuable by the government) tripled between the 2004-2005 school year and 2007-2008, while the number of students taking Japanese increased by only 17 percent. Only 10 states reported enrollment numbers for Arabic, but the 2,300 students counted represent a 172 percent increase over the 2004-2005 numbers (Koebler, 2012).

Japanese education faces yet another funding difficulty. According to Martha Abbot, ACTFA's executive director, "When a country's economy is strong, the government is often willing to support extending the learning of that language" (Koebler, 2012). During the 1980’s, at the peak of the Japanese economic boom, the Japanese government had been willing to do just that, backing Japanese language education abroad in such a way that resulted in the marked increase of Japanese programs. These initiatives were largely cut with the ensuing decline of the next two decades, bringing about the 
decline and eventual discontinuation of Japanese language programs throughout the United States. This stands in stark contrast to Mandarin Chinese, where the Chinese government maintains the ability to spend large amounts of money in order to increase interest in both its culture and language. Indeed, Abbot claims that "China is supporting and sponsoring teachers from China to extend the teaching of their language" (Koebler, 2012).

\section{Lack of Articulation}

The term articulation here means to connect various fragments such as individuals, administrators and teaching materials, involving Japanese language education in United States. Following are some examples of the lack of articulation as stated by Tosaku (2009).

1. A lack of established articulation between individual levels of Japanese language education.

2. A lack of communication within the region as to teaching materials, textbooks and supplemental materials.

3. A lack of networking among professionals (i.e. low membership rates in organizations).

4. A lack of clear articulation within K-12 throughout the region.

5. A lack of students continuing their study of Japanese from K-12 to the university level.

\section{Teacher qualification}

Towards the end of the Japanese Economic Bubble of the 1980's, there was interest in offering Japanese language courses in the United States. Interest was so great 
that educational institutions throughout the country quickly found themselves with a lack of qualified teachers. This deficiency was only mediated due to hiring of large number of individuals who wanted to become Japanese teachers, but did not necessarily possess all of the qualifications necessary to effectively teach the language. The consequence of the trend to hire these underqualified individuals can be seen today in the lack of Japanese language teachers with teaching certificates.

As necessary as it may be to train teachers certified in the Japanese language, the reality is that the number of universities that issue Japanese-language teaching certificates, (not to mention the number of education departments in universities or graduate schools specializing in cultivating Japanese-language teachers) is still quite limited.

To sum up the trend of Japanese language education overseas, Isoyama \& Lin (2006) present a diagram, Figure 1. that details the factors as part of a circle of decline at work within Japanese language education in the United States today: fewer learners, less funding, fewer full-time positions, less administrative influence, fewer courses and fewer programs. 


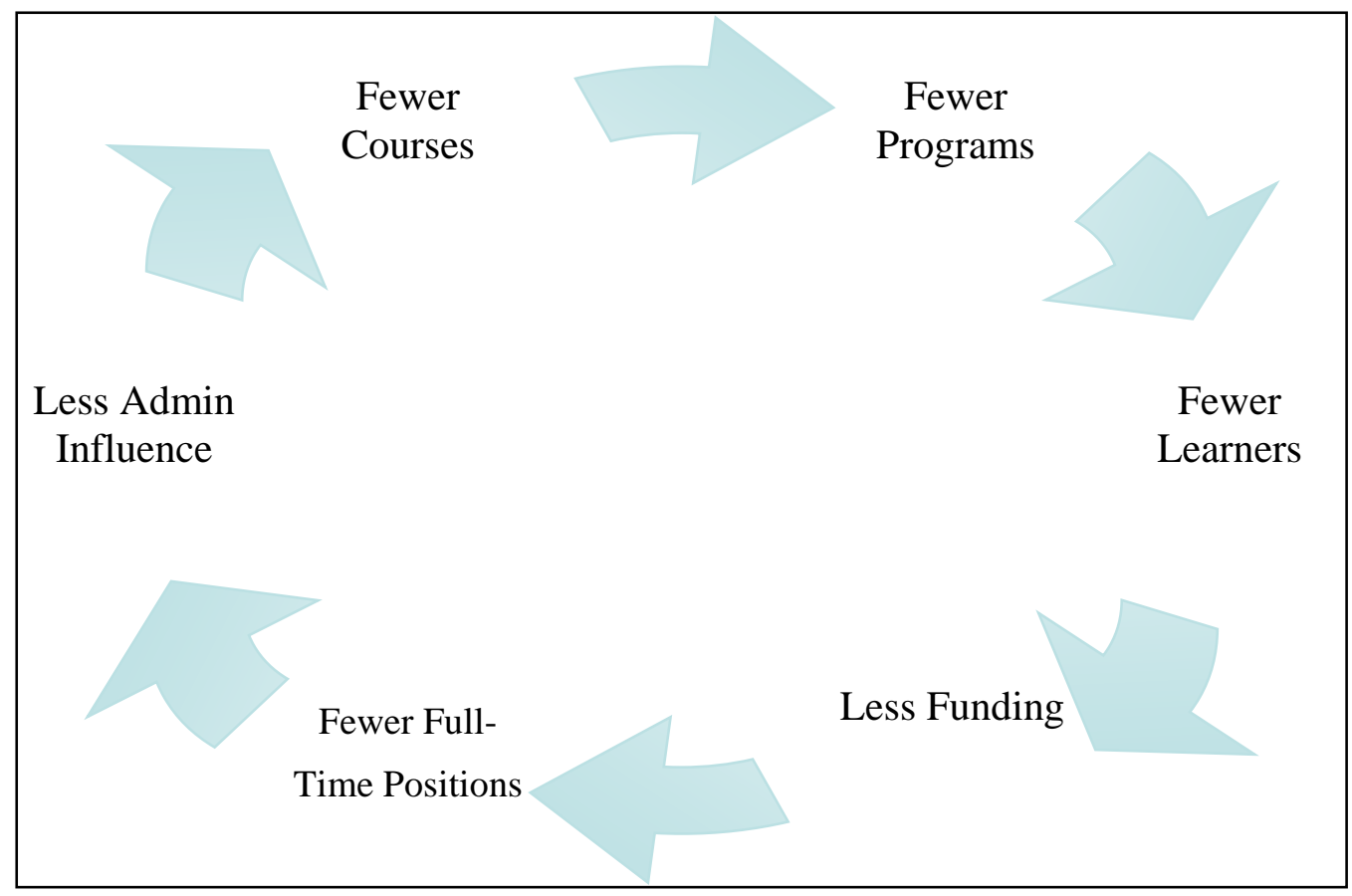

Figure 1. The cycle of Japanese language learning decline overseas according to Isoyama \& Lin (2006)

Isoyama and Lin (2006) highlighted three ways by which Japanese programs throughout the country could overcome these problems: advocacy, fund raising, and professional development. Advocacy, they maintain, should primarily be in the form of outreach by instructors of the language; university professors would visit high schools, high school teachers would visit middle schools, and so on in order to stress the value of early Japanese language education. Isoyama \& Lin (2006) and Tosaku (2009) all mention a need for the constant cultivation of Japanese teachers’ professional developmentspecifically, in the form of Japanese language pedagogy training from either universities or online programs like those provided by the American Association of Teachers of Japanese. They also agree that what is needed now is for each instructor to understand their school's politics and "social changes surrounding our occupation and respond to them” (Tosaku, 2009). 
To popularize Japanese language education, Tosaku includes the following:

(1) To raise the visibility of Japanese-language education, moving beyond the wall of the Japanese-language education circle.

(2) Demonstrating the presence of Japanese-language education at local or state foreign-language education associations, as well as at state departments of education and government.

(3) The popularization of activities in all levels of classes, schools, students' homes, communities, school districts, and state governments.

(4) Japanese-language teachers' associations to spread know-how on conducting popularization activities among Japanese-language teachers.

\section{New Movements for Japanese Language Education in the United States}

In recent years, Japanese language education in the United States has experienced at least four major developments that are oriented towards supporting advanced Japanese language learners and fostering clear articulation: 1) the publication of a new version of the popular textbook series Genki; 2) a revision of the Japanese Language Proficiency Test; 3) the reorganization of the American Association of Japanese Teachers; and 4) the American Association of Japanese Teacher's Japanese Online Instruction Network for Teachers.

\section{Genki: The New Edition}

Genki is the most widely used Japanese language textbook at the university level in the United States. It has been used at FIU since 2004, but had not been updated until the release of the second edition in 2011. As a result of the new addition, the textbook has been thoroughly enhanced. For one, many outdated words and expressions have been 
replaced with contemporary Japanese terms. More important, the Genki textbook's addition of "Culture Notes” (small asides at the end of each chapter's discussion of its grammar points that provide insight into specific aspects of Japanese culture) seems to reflect the trend of appealing to student interests in Japanese culture.

\section{The Revised Japanese Language Proficiency Test (JLPT)}

Since 2009, the JLPT has been offered twice a year in order to accommodate the growing number of applicants. To ensure the continuing relevancy and accuracy of the JLPT, the Japan Foundation and Japan Educational Exchanges and Services introduced a revised version of the test in 2010. There are three main revisions that have been made to the new JLPT. First, the new JLPT has expanded its mission from simply measuring linguistic knowledge to testing practical communicative competence. Second, the Japan Foundation has reorganized the testing levels of the JLPT. Citing the large difficultly gap between the Level 3 and Level 2 versions of the test and the desire to measure more advanced abilities with the Level 1 version, the JLPT's four-level system has been replaced with a five-level system. And third, the Japan Foundation has developed detailed descriptions of the practical abilities someone with a particular JLPT level certification can be expected to have (The Japan Foundation, 2008). These changes have resulted in a JLPT that focuses more on testing communication abilities and meeting more diverse student needs. Since 2012, the JLPT has been administered with the support of the American Association of Teachers of Japanese (AATJ), which hosts discussions on K-16 Japanese language education standards and other current issues related to Japanese education in the United States. 


\section{Restructuring of the Japanese Teachers Organization}

The restructuring of the Japanese Teachers Organization was done to create the American Association of Teachers of Japanese (AATJ), a non-profit, non-political organization of individuals and institutions seeking to promote the study of Japanese language, linguistics, literature, culture, and pedagogy, at all levels of instruction. The AATJ is the product of the consolidation of two national organizations: the Association of Teachers of Japanese (ATJ), founded in 1963, and the National Council of Japanese Language Teachers (NCJLT), founded in 1992. The AATJ believes that one organization will have a unified voice, strong support for educators K-16+, greater financial sustainability, better articulation, and a streamlining of resources (American Association of Teachers of Japanese, n.d.). That the JLPT has been administered with the backing of the American Association of Teachers of Japanese since 2012 can be seen as a testament to that organizations newfound solidarity and wide support base.

\section{JOINT (Japanese On-Line Instruction Network for Teachers)}

As previously mentioned, the limited number of locations at which a Japanese teacher is able to take Japanese-language pedagogy courses is a key element in the underqualification of many of the language's educators. In order to deal with this issue, AATJ started an online training program for Japanese-language teachers in 2008, called the Japanese Online Instruction Network for Teachers (JOINT). Individuals who take this program can earn credits at the university or graduate school level. If university and graduate school students who aim to become Japanese-language teachers enter a program like JOINT and acquired specialized knowledge and skills, their abilities as Japanese- 
language teachers would further improve, resulting in an overall increase in the quality of instruction (The Japan Foundation, 2009).

In short, from the perspectives of Japanese government and administrators associated with Japanese teaching and learning are making changes. These changes certainly represent a shift in the pedagogical nature of Japanese language education to a more culturally based framework as above.

\section{Recent Teaching Practices}

Recent trends in teaching practices in Japanese language instruction at the college level can be divided into two general categories. The first has been to link Japanese language education with education in Japanese culture and art, a method which introduces into the student a sense of Transcultural Competence. The second has been to link Japanese language education with other academic disciplines, instilling in the student Professional Competence.

The first trend can be seen in attempts to strengthen bridges between Japan Studies programs and Japanese Language programs at U.S. universities. This is evident at Emory University, the University of Notre Dame, and DePaul University, where efforts have been made to strengthen links between Japan Studies programs in East Asian Studies departments and Japanese Language programs that may be in Modern Language departments. In Language Across The Curriculum: "Introduction to Japanese Popular Culture” In the Spring 2009 Semester, Noriko Hanabusa discusses how the University of Notre Dame has worked to develop courses that provide students the opportunity to use advanced language skills in the context of a "content-based class" (AATJ, n.d.). 
The trend of linking Japanese language education with other academic disciplines can be seen in efforts made by college-level Japanese language programs to reach out to departments unrelated to East Asian studies. In Content-Based Japanese Language Courses for Graduate Students of International Relations, Eiko Ushida highlights the University of California, San Diego's efforts in developing Japanese language courses offered jointly by the Graduate School of International Relations and the Japanese Studies program; formal Japanese language courses built on the foundation of International Relations content (AATJ, n.d.). Similarly, in Japanese for Technical and Business Professions at the University of Washington: Curricula and Syllabi, Michio Tsutsui provides an overview of efforts to link Japanese language education with the University of Washington’s engineering school (Tsutsui, 2010).

\section{Japanese Programs in Miami-Dade County}

There has been a decrease in the number of students who are taking Japanese in primary or secondary education institutions in the United States, and this trend can be also seen in South Florida, specifically, Miami-Dade County. An analysis by the Japan Foundation suggests that this can be directly linked to the enactment of The No Child Left Behind Act, which has required elementary and secondary public schools to hire only officially licensed teachers to teach core subjects. This has posed a serious difficulty for Japanese language instruction given that the limited number of Japanese-language teacher licensing programs has been further reduced. In addition, public schools tend to reallocate their budgets to enhance main-core subject courses by cutting down or closing elective courses. Most important of all, an expansion of Chinese language programs has impacted Japanese language programs, especially in K-12 schools. Data collected over 
the past decade on Japanese course offerings in 2003, 2008 and 2013 throughout K-16 reveals that the number of schools in K-12 that offered Japanese language decreased from 6 to 3 in Miami-Dade County from 2003 to 2013. As recently as 2003, there were no Chinese language programs in Florida public schools. Since then, Miami-Dade school systems have started Chinese programs and in 2008 there were 13 schools offering Chinese language, although by 2013 the number has decreased to 8 . At the university level, there were 3 universities in the county offering both Chinese and Japanese language courses in 2008 and 2013. This relates interestingly to the setting of the current study (FIU); because of the limited amount of Japanese courses offered in K-12, there seems to be a steady flow of students entering the university who are enthusiastic about committing to the language. In addition, FIU is the only university in South Florida that offers advanced Japanese language courses and other Asia and Japan-related interdisciplinary courses. It also offers a BA and an MA degree in Asian Studies, with the recent addition of both a Japanese Area Studies major and a Japanese Language and Literature minor in 2013.

\section{Japanese Program at FIU}

Teaching Japanese language and culture for the Modern Languages Department and Asian Studies program at FIU for a little over 15 years has allowed the researcher to closely observe the rapid growth of the Japanese and Asian Studies programs at FIU in Miami. Throughout the course of this past decade, enrollment for Japanese language and culture courses has increased more than five-fold, and the program is still expanding despite the recent national trend toward increasing Chinese language and culture course offerings at both the university and K-12 levels. The researcher started teaching as the 
only part time instructor, but the researcher now is a full-time senior instructor, accompanied by one tenure track Japanese professor in Japanese literature and culture, another full-time instructor, and three dedicated adjunct instructors.

To fully understand the growth of the Japanese program at FIU, it is necessary to discuss the development of the Asian Studies Program. Over the last decade, the Asian Studies Program, under the leadership of Dr. Steven Heine, has successfully developed and strengthened its many academic programs and hosted numerous student and instructor activities and opportunities, receiving nearly \$2 million to date in nation-wide competitive grants from various institutions. These grants have helped create more than several full-time faculty positions which have been crucial to the expansion of the program. Asian Studies also facilitates cultural and commercial exchanges and promotes networks with various other institutions in South Florida.

The Japanese language courses are offered by the Department of Modern Languages, currently chaired by Dr. Pascale Becel who has been extremely supportive of the Japanese Program. Due to her support, the support of Asian Studies, and the collaboration between the two units, the Japanese program has expanded and thrived at FIU. In 2015 there over 500 students currently enrolled in various levels of Japanese language courses.

\section{Summary}

This literature review began with a brief background of motivation and L2 motivational self-system. The second section provided an overall picture of foreign languages education and the trends in U.S. higher education. Basically, the reasons and purposes for learning Japanese language overseas are reflected in new movements, 
theories and practice for Japanese language education in the United States. Today, many students seem to be interested in Japanese culture. Clarifying descriptions of different levels of JLPT is useful along with an addition of another level of the test. Restructuring of professional organizations will create articulations in all levels and more concrete professional networks. Lastly, professionals in Japanese language education recognize the need to narrow the gap between the subject of the Japanese language and other nonlanguage subjects in the field of Japanese Studies.

The last two parts of the chapter address the status of Japanese programs locally and the growth of the current Japanese program at Florida International University. 


\section{CHAPTER III}

\section{METHODS}

The purpose of this study was to examine the reasons and purposes of nonJapanese undergraduate students for taking a beginners’ Japanese language course at Florida International University. This chapter outlines the methods used in this study, starting with the research question presented in Chapter 1 . The rest of this chapter consists of the following sections: research design, setting, sampling, participants, data collection, data analysis procedure, data management, delimitation of the study, role of the researcher, researcher's subjectivity, and integrity measures.

\section{Research Question}

This research was undertaken to answer the following question: What are the reasons and purposes of non-Japanese undergraduate students for taking a beginners’ Japanese language course at Florida International University?

\section{Research Design}

This research design utilized a qualitative research design. Strauss and Corbin (1990) described qualitative research as any kind of research that produces findings not arrived at by means of statistical procedures or through other means of quantification, and claim that qualitative methods can be used to better understand any little-known phenomenon. Maxwell (1996) further stated that "the strength of a qualitative research method is in understanding the process by which phenomena take place” (p. 59). The research design was the strategic outline (Johnson \& Christensen, 2004) guiding the answering of a research question. 
In the current study, data were collected through one-hour in-depth semistructured individual interviews with 12 non-Japanese undergraduate students who were enrolled in beginners' Japanese language courses at FIU. Phase I of the interviews was directed to all 12 students at the beginning of the courses. As two students dropped the courses during the semester, Phase II involved the remaining 10 non-Japanese undergraduate students at the end of their respective courses.

The main questions, along with follow-up questions and probes, were prepared in advance as an interview protocol (Appendix A) based on the L2 motivational self-system model in the form of an interview guide centered on the responsive interviewing model (Rubin \& Rubin, 2005). In order to reflect each dimension of the L2 motivational selfsystem in Phase I, questions were asked relating to (a) aspirations and goals; (b) perceived obligations and responsibilities; and (c) perceived L2 learning experiences, in general terms and in Phase II questions were asked relating to (a) aspirations and goals; (b) perceived obligations and responsibilities; and (c) reflections on one semester of L2 Japanese learning experience at FIU.

The researcher sent an e-mail to all Japanese instructors two weeks prior to them teaching JPN 1130 (Beginner’s Japanese) in the fall semester of 2014. (See Appendix B) The e-mail gave instructions on exactly what to say and do during the first day of class when asking for students to voluntarily participate in this study. The researcher made a copy of the same instructions and a form asking students if they would participate in the study, and to provide the researcher with contact information so that the researcher would be able to reach them at a later date. (See Appendix C) Instructions and inquiry forms for students in each class were placed in the instructors' mail box. Inquiry forms were 
distributed by three different instructors towards the end of their first class. None of the participants were students of the researcher.

Participants signed a written consent form (See Appendix D) before the recorded interview started. At the beginning of the interview, detailed explanations on the terms of participation were provided, highlighting that: (a) the student's participation was completely voluntary, (b) they had the right to withdraw from the study at any time without any penalty, (c) their personal information and any information provided during interviews would remain confidential, (d) all related materials, including the researcher's notes, would be securely stored in my personal computer which requires a password, (e) information contained during the interviews could be used in materials to be made available to the general public, (f) a participant would remain anonymous if they wished, and (g) the results of this study might be published.

\section{Setting}

FIU's dynamic student body reflects the vibrant diversity of the South Florida area population. The FIU student body consists of 61\% Hispanic, 15\% White NonHispanic, 13\% Black, 4\% Asian or Pacific Islander, and 7\% other minority groups (Florida International University, 2014). Moreover, FIU is the fifth largest university in terms of student enrollment in the nation. It serves a student body of over 54,000, and offers more than 180 bachelors, masters and doctoral programs in a variety of fields.

The university's Japanese program has experienced significant growth in recent years with an almost 10-fold increase in enrollment in the last decade. In the first days of the program the only staff was an adjunct instructor; in 2015 there are currently two fulltime instructors, one-tenured assistant professor with a joint hire with the Asian Studies 
program and four adjunct instructors. There are variety of interdisciplinary courses offered such as cinema, conversation, composition, literature, translation and fully-online courses for beginners' Japanese language. Additionally, over 250 students enroll in Japanese languages courses at all levels each semester. The enrollment increase was significant given: (a) the great geographic distance between Japan and Miami; (b) the limited local Japanese population; (c) Miami’s predominantly Hispanic population; (d) Japan's experience of a devastating earthquake and its aftermath in March, 2011; and, (e) the closing down of several Japanese programs in K-12 in Miami-Dade County public schools.

There are two academic units that have been instrumental in the development of FIU’s Japanese program: the Asian Studies program and the Modern Languages Department. The Japanese Area Studies Program falls under Asian Studies program and the Japanese Language Program falls under the Modern Languages Department. Both the Modern Languages Department and Asian Studies program are housed within the School of International and Public Affairs (SIPA), launched in Spring 2009. The Asian Studies program, under the leadership of director Dr. Steven Heine, was created in Fall 1997 and has grown rapidly into an interdisciplinary program with a B.A. (implemented in fall 2002), an M.A. program (implemented in fall 2005), a minor, and several specialized undergraduate and graduate certificates, including Japanese Studies, Chinese Studies, and Asian Globalization and Latin America certificates. Japanese courses form a key component of the newly established Japanese Area Studies B.A. offered by the Asian Studies Program, as well as the minor in Japanese Language and Literature offered by the Modern Languages Department. The Chair of the Modern Languages Department, Dr. 
Pascale Becel, mentioned in Flavia Iuspa’s (2010) dissertation entitled Assessing the Effectiveness of the Internationalization Process in Higher Education Institutions: A Case Study of Florida International University that the Department of Modern Languages is nearing the capacity to propose a major in Japanese. The Department of Modern Languages’ Japanese Language and Literature minor and the Asian Studies program’s Japanese Area Studies major will serve as stepping stones for the creation of a Japanese Language and Literature Major in the near future.

\section{Sampling}

This study made use of “purposive sampling” (Patton, 2002), a technique that allowed the researcher to choose a study population on the basis of both the researcher's familiarity with her subject and the intent of the study at large. The target population was composed of students who enrolled in beginners’ Japanese language courses at FIU. A sample was selected on the basis of a particular set of characteristics - in this case nonJapanese undergraduate students who decided to enroll in beginners’ Japanese language courses during the fall semester of 2014. Twelve non-Japanese undergraduate students were randomly selected using proportionate strategy allocation to balance gender of the participants.

As for sample size, Guest, Bunce and Johnson’s (2006)’s study and conclusion suggest "a sample of six interviews may [be] sufficient to enable development of meaningful themes and useful interpretations" (p.78). Patton (2002) states, "In-depth information from a small number of people can be very valuable, especially if the cases are information rich” (p.244). 
According to a study conducted by Dörnyei and Schmidt (2001), in which examines the motivations and attitudes of Japanese learners at a university in Hawaii, “developmental considerations are important in understanding students’ language motivation and attitude” (p.451). Through their surveys, Dörnyei, Z., \& Schmidt also found that fourth year students in particular mentioned that their interests in Japanese language and culture increased after they entered college. The reason of selecting beginners' language learners for this study at FIU was that the researcher believed that the chances of discovering students' original reasons and purposes for studying Japanese would increase by interviewing students who were relatively new to the college experience. This is in contrast to upperclassmen, whose motivations may have shifted in relation to the various experiences and encounters of collegiate-life. The reason why the researcher chose the first day for the inquiry form to be distributed is that students would not be acquainted with their peers and their professor on the first day of instruction, and as such they were likely to pay more careful attention to the inquiry form.

\section{Participants}

Undergraduate students enrolled in Japanese I (face-to-face beginners’ courses) at Florida International University's Modesto Maidique campus in Miami, Florida were selected for this study. FIU was chosen because of its proximity to the researcher, as well as the researcher's 15 years of knowledge and background within its Japanese program, Asian Studies Program and Modern Languages Department.

In fall, 2014, there was one fully-online beginners’ Japanese course with 24 students. Three were three face-to-face courses, making a sub-total 68 students. In total, there were 92 students enrolled in beginners' Japanese courses. The three face-to-face 
courses were taught by three different instructors other than the researcher. From among those who agreed to participate in the interviews, 4 women and men with ages ranging from 19 to 27 years old were randomly chosen using a proportionate strategy allocation. They were contacted via phone, and all individuals agreed to participate in the project and set up the schedule to meet with the researcher. Table 2 provides more details on the participants in the order they were interviewed. To ensure confidentiality, the pseudonyms are used throughout the dissertation.

Table 2

Individual Interview Participants’ Profiles

\begin{tabular}{|c|c|c|c|c|c|}
\hline Pseudonym & Age & Gender & Major & $\begin{array}{l}\text { Languages } \\
\text { E=English } \\
\text { S=Spanish }\end{array}$ & Yrs. in U.S. \\
\hline Sofia & 24 & $\mathrm{~F}$ & $\begin{array}{l}\text { Switching from } \\
\text { Anthropology to } \\
\text { Asian Studies }\end{array}$ & $\mathrm{E} \& \mathrm{~S}$ & Entire life \\
\hline Santiago & 19 & M & Undeclared & E \& some S & Entire life \\
\hline Alejandro & 19 & $\mathrm{M}$ & $\begin{array}{l}\text { Switching to } \\
\text { Hospitality } \\
\text { Management }\end{array}$ & $E \& S$ & Most of his life \\
\hline Mateo & 21 & M & Psychology & $\mathrm{E} \& \mathrm{~S}$ & Entire life \\
\hline Alvare & 23 & $\mathrm{M}$ & Psychology & $E \& S$ & Entire life \\
\hline Victoria & 19 & $\mathrm{~F}$ & Asian Studies & Tagalog \& E & Entire life \\
\hline Diego & 27 & M & Japanese Area S & $\mathrm{E} \& \mathrm{~S}$ & Entire life \\
\hline Daniel & 20 & M & Biology & $\mathrm{E} \& \mathrm{~S}$ & Entire life \\
\hline Tomas & 27 & M & Computer Science & $\mathrm{E} \& \mathrm{~S}$ & Entire life \\
\hline Mary & 19 & $\mathrm{~F}$ & English & $\mathrm{E}$ & Entire life \\
\hline David & 24 & M & Mechanical Engineering & $\mathrm{E} \& \mathrm{~S}$ & Most of his life \\
\hline Erica & 21 & $\mathrm{~F}$ & Asian Studies & $\mathrm{E}$ & Entire life \\
\hline
\end{tabular}

Note: Strikethrough indicates students who dropped the course before Phase II. 
Participants were from different majors who, with just one exception, had lived their entire lives in the US. However, most were bilingual speakers of English and Spanish. In addition, most of them could have taken Spanish as a language requirement for their major and completed the courses with ease, but chose to take Japanese instead.

Foreign language requirement varies depending on a student's major. Asian Studies majors are required to take Chinese, Japanese or an equivalent language up to the intermediate level, consisting of the first four consecutive courses offered at FIU.

\section{Data Collection}

The goal of qualitative research is to understand a subject from the perspective of the participants (Bogdan \& Biklen, 2003) and its data includes interviews, observational field notes, videos, journals, memos and other forms of written materials (Silverman, 1993). Rubin and Rubin (2005) said that qualitative interviewing projects are ideal for describing — how and why these things change over time—and exploring new areas, as well as discovering and unraveling intriguing puzzles. Moreover, a qualitative research interview seeks the meanings of central themes in the "life world" of the subjects (Kvale, 1996).

The inquiry form was distributed in the last 10 minutes of the first day of the fall 2014 semester, after the instructor completed his/her instructions for the class. At this point, a short written consent form prepared by the researcher was distributed to all students in class for them to sign. Students who did not wish to sign and participate answering an inquiry form were advised that they could leave the classroom after the instructor announced that an inquiry form was to be distributed. 
The researcher contacted possible participants by phone who agreed to be interviewed in person. The researcher and the possible participants scheduled a time to meet in the researcher's office first and decide where exactly at FIU the participant desired the interview to be conducted. This approach involved the preparation of an interview guide that listed a pre-determined set of questions that were to be explored during an interview. There was a great deal of flexibility in this approach.

In order to get repeated access to information contained in interviews each was recorded with the researcher's digital recorder after obtaining the interviewee's permission. Following Strauss and Corbins's (1998) suggestions, the researcher listened to the audio recordings immediately after every interview in order to reorganize notes taken during the session. The notes included a paraphrase, phrase, heading, and label that described what the researcher was seeing in the passages or quote that was important and relevant for answering the research question.

As mentioned earlier, two participants dropped the course during the semester: one at the beginning of the semester and another towards the end, thus, leaving 10 participants for the Phase II interviews. Both instructors did not know exactly why the two students had dropped the course. They suddenly stopped attending classes. According the instructor of each student, one student was not passing the course, but the other student was. For Phase II, all of the remaining participants came to the interview on time, except one participant who forgot and made another appointment. One participant did not permit the Phase I interview to be recorded. The participant who refused did so for a personal reason. The researcher gathered data for this particular interview by speaking slowly and taking as many notes as possible. 
Each interview lasted approximately one hour and roughly consisted of a 5minute introduction and warm-up and questions based on (a) 15minutes based on aspirations and goals; (b) 15 minutes based on perceived obligations and responsibilities; (c) previous L2 learning perception in general (Phase I) and reflections of Japanese learning experience at FIU, and 10 minutes of summarizing. This was a rough estimate of the interview only to make sure that each dimension of the conceptual framework would be discussed therein. The interview protocol consisted of enough questions for the researcher to start from to gain a wide range of information. Considering the focus on the future-projection of the L2 self, the researcher treated the L2 motivational self-system as dynamic and the system that is subjected to change (Dörnyei \& Ushioda, 2009), thus a two-phase study was appropriate and meaningful.

Interviews were also recorded with the researcher's iPhone and recordings were saved in the researcher's office desk computer immediately after the interview. The researcher's computer required a password to be accessible. Each participant signed a copy of the informed consent release form, which was created by the researcher and approved by the Florida International University Internal Review Board with human subjects (See Appendix D). A copy of the consent form was given to each participant for their record. All 12 interviews for Phase I and 10 interviews for Phase II were transcribed and coded by the researcher. The researcher initially intended to use software to transcribe interviews. However, the software detected the accents and stuttering, but couldn't understand what was being said well enough to accurately transcribe several students' interviews. In addition to the issue, a few participants had extremely soft voices and, unexpectedly, half of the participants stuttered, some severely. According to the 
instructors, they did stutter in classes also. Thus, the researcher did not use the software for transcribing.

Overall, the interview framework was designed to minimize the effects of interviewer bias towards the subjects, particularly where the interviewer's expectations may have influenced their insignificant gestures (such as frowning or smiling in response to information provided by the subject), inadvertently leading to an influence on the subject's responses.

\section{Data Analysis Procedures}

Audio recordings were transcribed and coded by grouping data into meaningful patterns and themes by the researcher. This construction involved abstracting concrete descriptions into categories or themes (Merriam, 1998). This process also included abbreviating words, demarking colored dots, and using numbers (Bogdon \& Biklen, 2006), in addition to identifying similarities and differences for developing and refining themes, and possibly sub-themes (Ryan \& Bernard, 2003). In addition, potential themes were found by identifying reoccurring matters and by paying close attention to the number of times they appeared in the data. The codes were grouped and ranked, and presented as tables or charts accordingly. For this process, the researcher used software called ATLAS ti. The coding process allowed the researcher to make connections and develop meanings from interviews in more organized way because she was able to play around with different ways to organize the themes to create conceptual schema.

Collected data were analyzed using inductive analysis. After completing the inductive analysis of Phase I, the inductive analysis of Phase II was conducted. Phase I 
data was analyzed before the Phase II interviews. Then the comparative inductive analysis of Phase I and II was conducted.

Inductive analysis involves discovering patterns, themes, and categories in the data (Patton, 2002). Interview questions were constructed based on 3 interconnected categories of the L2 Motivational Self System: (a) Ideal L2 Self (b) Ought-to L2 Self, and (c) L2 Learning Experience. Collecting the data before and after the semester, the researcher was able to see the participants’ changes in their motivations, attitude and vision related to Japanese language learning including their inner self.

\section{Inductive Analysis}

Each of the interviews was coded with different colored erasable pens representing common themes. The researcher focused on the importance of allowing themes and patterns to emerge without assumptions. Findings emerged through the researcher's interactions with the data over time. The initial process of coding began with the second reading of each transcript to identify patterns that were turned into “meaningful categories and themes” (Patton, 2002, p. 463). The following specific steps were completed for each participant:

- All 12 interviews were recorded and transcribed by the researcher.

- Each interview was read from start to finish without coding first.

- On the second read, relevant word(s), statements, phrases were underlined or marked to develop primary codes.

- Similar primary codes were grouped and themes were sought using different erasable colored pens. 
- Similar topics were clustered and sub-topics were created and organized into conceptual groupings.

- Transcripts were reviewed to consistently compare these themes. Spelling and minor errors were corrected.

- Tentative themes were created according to the researcher's coding.

- Tentative themes were compared across all transcripts to identify similarities.

- Themes and sub-themes were created.

This constant comparative method during the data analysis process offered the researcher the means to delve into the participants' messages between words and to see emerging thematic categories. The researcher used software known as ATLAS. to manage the data for organization purposes which made retrieving easier and helped organize the large amount of data.

\section{Data Management}

The measures were in accordance with guidelines in the Florida International University Regulations for Thesis and Dissertation Preparation Manual (2009). Throughout the study, participants were identified unless they wished, and they also were allowed to withdraw at any point. Pseudonyms were assigned to protect identities. All data will be stored and kept for three years after the end of the study.

\section{Delimitation of the Study}

The research focused on non-Japanese undergraduate students enrolled in beginners' Japanese language courses students who were most likely new to the program and FIU, as lower-division students tend to take beginner's classes. 


\section{Role of the Researcher}

In qualitative research, "the researcher is the primary instrument for data collection and data analysis and is more concerned with process rather than outcome” (Merriam \& Simpson, 1995, p. 98). The researcher plays a critical role in the study’s understanding of the phenomenon at hand. The researcher works at FIU and is deeply familiar with the history and the development of its Japanese program, as well as with the students who have taken Japanese language courses over the past 15 years. I started out as the only Japanese instructor in the year 2000, with approximately 30 students per semester in total, and our Japanese program now has a tenure-track assistant professor in Japanese language and literature, two full-time instructors (including myself), three adjunct instructors, and a student enrollment that has increased consistently and rapidly.

I was born and raised in the rural city of Kurume in the Fukuoka prefecture of Japan. It was there that I began to ask myself the existential questions that people across the globe ask themselves as teenagers: “What am I doing here?” "What am I here for?” I also questioned the methods of English as a Second Language instruction and the Japanese educational systems system as a whole. English classes consisted of rote memorization of English vocabulary words as if they were symbols of chemical elements to be learned and reviewed, and I felt as though we were simply being molded to pass the university entrance exam, and not actually expected to use the language. This was likely the case; even today, because if a student fails the exam, no second chance is given. Some students still commit suicide for their failure and even when they fail their exam. I was considered rebellious, both by the Japanese educational system and the wellstructured society of Japan. I simply felt like I did not fit in and that I did not belong 
anywhere. I longed to fulfill my life and be true to myself. One day, the strange combination of learning about the Glenn Miller Band in English class, learning about Martin Luther King, Jr. on Japanese TV, and reading the classic autobiographical novel "No Longer Human" (人間失格 Ningen Shikkaku) resulted in the spark that would drive me to get up and leave Japan.

I dreamed about leaving Japan and also traveling west to some far away country that I perceived as an unknown part of the world where people were able to be accepted in all sorts of circumstances, regardless of their origin. This illusion was later shattered by the discriminatory treatment I experienced, but even that became part of my growing motivation to become a bridge between Japan and the United States.

Generally speaking, the main object of interest in a study is impacted by the researcher's experiences. My motivation began in my youth when, at the age of 15, I left my native Japan as a high school exchange student to the United States. I spent the next year near Lancaster, Pennsylvania, where I was surrounded by Mennonites and Amish people. Not only did I experience culture shock relative to American culture, but had also to contend with the culture of Mennonites and Amish people. At first, I did not understand why they had to climb up on a slope pushing horses and buggies on a heavy snowy day when many cars drove past them, but the more time I spent with them, the more respect I developed towards their way of living.

After spending a year in Pennsylvania as a high school exchange student, I went back to Japan to finish my BA in Kyoto and devote myself to Karate-do as the captain of the university Karate team. I was so immersed in my training that my most predominant memories of Japanese college life have to do with Karate-do training with Sempai and 
Kohai. After graduation I received the Rotary Foundation Ambassadorial Scholarship to complete my Master's degree in the United States. As a student, I was offered a job teaching Japanese language and culture as an adjunct instructor in Miami, while simultaneously rolling sushi to make ends meet and continuing daily Karate-do training. The more I was exposed to life in the United States, or rather Hispanic culture because of Miami’s demographics, the more I missed the Japan that I had at one point despised. Training in Karate-do in Miami along with all non-Japanese practitioners with a Cuban Sensei (excluding the masters), was a great reminder of the roots that I could no longer deny. Above all, teaching Japanese language and culture to students who were highly motivated and observing their appreciation of Japanese culture and language gave me a new appreciation for my own culture and the students at FIU.

My interest in the subject of this dissertation is the product of my 15 years at FIU. As the Japanese program grew, I came into contact with an increasing number of students who resembled Otaku (someone with obsessive interests, usually in popular culture such as anime and manga) and Hikikomori (someone who suffers from social withdrawal), and could not help noticing that these characteristics seemed particularly unique to students who were intrigued by the Japanese language and culture. I began to wonder what motivates students to study the Japanese language and culture at FIU.

\section{Researcher's Subjectivity}

Given my geographical distance from Japan in the last twenty years, supplemented by travelling back and forth every year, I have been able to see changes in Japanese culture and behavior more objectively. These potentially confounding variables and possibilities for bias are inherently present in qualitative research and important to 
consider in the process of analyzing data. In addition, it is only natural that human instruments have shortcomings and biases that might have an impact on research. Rather than try to eliminate these subjectivities and biases, it is important to both identify and monitor them, so as to remain aware of how they may be shaping the collection and interpretation of data (Peshkin, 1988). In his writing Peshkin (1988) went so far as to make the case that one's subjectivities "can be seen as virtuous, for it is the basis of researchers' making a distinctive contribution, one that results from the unique configuration of their personal qualities joined to the data they have collected.” (p. 18).

\section{Integrity Measures}

First, the researcher kept a research experience journal for reflexivity as a strategy. Reflective journal entries were used in data analysis to create transparency and also to clarify subjectivities (Ahern, 1999). The entries started from the day the researcher e-mails all the instructors who would possibly teach Japanese beginners' classes in Fall 2014. The researcher wrote at least two journal entries each week to help examine "personal assumptions and goals" and clarify "individual belief systems and subjectivities” (Russell \& Kelly, 2002, p. 2). Second, multiple sources of evidence were collected. In this study, document analysis, and semi-structured interviews will be used to give a more detailed and balanced picture of the phenomenon in question (Altrichter, Feldman, Posch, \& Somekh, 2008) to ensure that proposed interpretations or assertions are credible (Newman \& Benz, 1998). Third, the researcher would document referential materials and leave accurate documentation so that another researcher can easily replicate the research (Newman \& Benz,1998). 


\section{Researcher's Journal}

The researcher began to keep a journal a week before the project started. The researcher also took notes in the same notebook as a reference guide both during and after each interview (Patton, 2002). The latter entry was done directly after each interview. Both entries included what the researcher noticed about the participant, the participant's feelings, the researcher's reactions and feelings, new ideas, biases, emerging themes, thoughts, and reflections related to the participant and the study. Many of the notes that were taken during the interview were impressions, noted in key terms, phrases and words. The researcher found journaling and taking notes extremely helpful since the amount of collected data, even though voluminous, was recorded in writing which allowed the researcher to go back, review and reflect on the data as needed and desired. 


\section{CHAPTER IV}

\section{FINDINGS}

Using the data gathered in the in-depth semi-structured individual interviews, this chapter presents the description of themes, sub-themes, and trends that emerged from inductive analysis in Phase I and Phase II along with a comparative analysis of both phases. Specific conversations and responses are disclosed in this chapter. Participants’ pseudonyms and transcript line numbers are indicated for each quote in the format of “Diego, lines 298-300”.

\section{Inductive Analysis (Phase I)}

Through thematic inductive analysis, the researcher found two major themes that emerged from the collected data. They were: attraction to Japanese culture and the utility of using the Japanese language. The researcher has defined utility as practical use of the Japanese language. The term culture is defined by Zimmerman (2015) as “the characteristics and knowledge of a particular group of people, defined by everything from language, religion, cuisine, social habits, music and arts. The Center for Advanced Research on Language Acquisition goes a step further, defining culture as shared patterns of behaviors and interactions, cognitive constructs and understanding that are learned by socialization. Thus, it can be seen as the growth of a group identity fostered by social patterns unique to the group.”

Attraction to Japanese culture appeared to be the main motivation for participants to obtain their purposes which were acted out through the utility of using the Japanese language. Within the culture theme there were three sub-themes, namely anime and manga, martial arts, and games. The participants frequently used the term "anime” to 
refer to manga and vice versa without distinguishing between the two terms. The term "anime” is used here to include or denote manga unless there is a specific reference to manga. The researcher also subsumed computer games, Internet games, video games, Nintendo, phone games, TV game shows into the term "games". Among the sub-themes, anime and manga was the leading reason for developing an interest in Japanese language and culture. As for the second main theme, utility, the emergent sub-themes were study abroad and employment - both of which were connected to aspects of living in Japan.

The researcher understood the word “purposes” as an individual’s starting point of taking action to pursue something, which, in this case, is associated with attractions to or fascination with Japanese language and culture. "Reasons," on the other hand, were defined as a type of justification of such "purpose.” The diagram below sets out the relationship among reasons, purposes and motivations specific to this study as established from inductive analysis in Phase I.

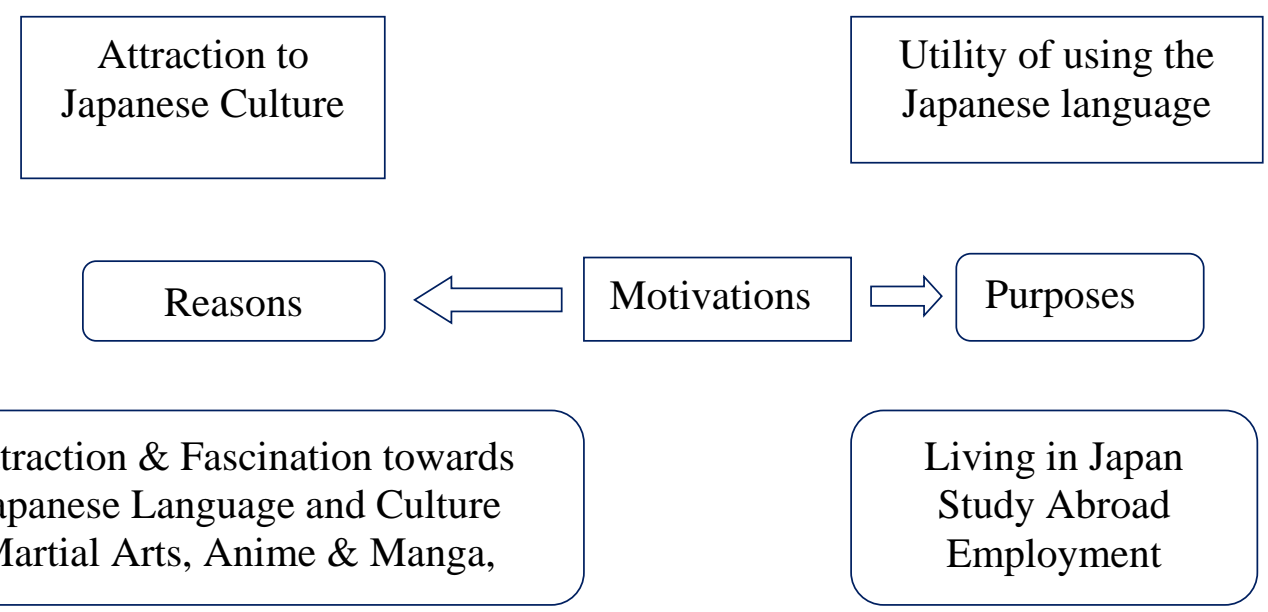

Figure 2. Motivations Reasons and Purposes. 


\section{Anime and Manga}

From the beginning of the interviews, all but one of the 12 participants in Phase I attested that anime and manga had influenced their interest in Japan, particularly in their younger years. For example, when the researcher asked Mateo why he chose to take a Japanese language course at FIU, he answered that he had been interested in anime since he was 5 or 6 years old (although he was unaware of anime being Japanese origin). He responds:

"Most of spark initially came from, of course, entertainment, anime.... I am sure you have heard about that, but let's see as a kid, I obviously, most of us kids, watch cartoons and things like that. I watched a lot of cartoons even though I did not know that they were Japanese, but with introduction of Internet and all of that, became interested and see the relationship... Wow... this is interesting and different than American cartoons. Japanese cartoons, yes, it had original language, and for me it was pleasurable to hear native voices.” (Mateo, line 17)

Like Mateo, David, who is an electrical engineering major taking the course for non-credit, was completely unaware that anime was Japanese animation when he was watching “Dragon Ball Z.” He only began to associate anime with Japan when he read Naruto (Manga series). He responded to the researcher's question by stating that it was his interests in anime and manga that driven him to take Japanese language course at FIU. For Diego, while there were several factors behind his interest in Japanese language and culture, anime was also a large part of the reason for taking Japanese. Anime had been a significant part of his life ever since he was young. He attributed this to a childhood friend who was a Japanese native, and described his first encounter with her. 
Diego: "So I was with first, second and third grader in a Montessori school. I have become friends with the third grader, and she had just moved from Tokyo to Miami. We both felt alienated.”

I: "How come she had felt alienated?"

Diego: "She said that she wanted to go home, Japan.”

I: “Did she speak English?”

Diego: "Yes, she did, but...All I know is that we both hit it off very well. We quickly became friends from the very beginning. She exposed me to anime and stuff like that. Of course, for young boys, it is very easy to get into those... She was very nice and an amazing artist. Back at that time I was very much into Power Rangers so every day, she would draw me a different character.” (Diego, lines 22-26)

Daniel, who said he used to read manga (and to this day extensively watches many anime series and manga), also mentioned that anime has been his inspiration for learning Japanese at FIU. When asked how his life had been impacted by Japanese culture, he said: that it was “...through martial arts and anime. It changed how I see my life.” When asked to elaborate on that answer he said

"I guess it made me more mature faster. Because when I see American culture, it is about partying and all of that, drinking and all that, but when I see anime, it was not about partying. It was all about serious stuff” and that he started to see his life and life in general from different perspectives and "through Japanese lenses." (Daniel, line, 95-101) 
Daniel is from Central America, and stated that American culture was all about “partying and drinking.” He also described anime as something that had changed his life, quite similar to Diego’s circumstances. Because of anime, both Daniel and Diego stated that they see life from a different perspective that is through Japanese lenses. Daniel also talked about how good he felt when he learned Japanese and understood songs and shows that were in Japanese language. (Daniel, lines 200-201)

A similar conversation ensued with another participant, Tomas, who shared similar personal characteristics as Daniel. They both were reserved and quiet. Also, they seemed intimidated at times. In Tomas's case, he had had difficulties finding motivation in life and said that when he was growing up that he was only surrounded by people who spoke Spanish and was secluded in a Mexican community in Texas. He stated that he first started to be interested in Japanese around 10 or 12 when watching Japanese anime shows particularly Dragon Ball Z. He said that it was different from American anime "because they were more dramatic" and that

“They are very visual like less cartoonish like more... more serious. The story lines... they have different atmosphere. Umm...most of American story lines are not so continuous. For me it was more engaging. You are always waiting to see what is next, expecting something, what is gonna happen next...It was more like a TV drama compared to cartoons.” (Tomas, lines 117-190)

Sofia was extremely intrigued by Japanese animation. Sofia who, when interviewed had just changed her major from Anthropology /Sociology to Asian Studies after a semester of studying Japanese language at FIU said: “Since I was 16, I kinda fell in love with the culture. I did watch anime as most children in our generation did, Sailor 
Moon and Pokemon and etc.” (Sofia, line 13). Similarly, Santiago said that “... the first reason that I have ever had for studying Japanese language was to watch anime without having read the subtitles. Then after two years of Japanese (in high school), it occurred to me that I will never be able to watch anime without subtitles”. (Santiago, line 68) He said he realized how difficult it was to learn Japanese language in Miami. After the semester that he participated in this study, he was accepted to participate in a one-year exchange program in Japan in the following year through an exchange program provided by the Office of Study Abroad at FIU.

Victoria also watched a lot of anime when she was young, especially anime called Naruto which helped her cope with the hardship she experienced as a young child. (Victoria, lines 199-202) She said that her father was an alcoholic and her parents used to have serious fights over finances and that she was told that she could not say anything about their fights, so she did not tell anyone. She coped with these situations by watching anime called Naruto. Other participants also mentioned similar situations and said that they also used watching anime and manga as some type of coping mechanism.

Alejandro's response as to what interested him in Japan and influenced him to start learning Japanese language was a connection through his girlfriend.

“.... about 3 summers ago when she came back from japan. That is the time when I started being interested in Japan. She brought back a lot of stuff from Japan, and what is this...what is this... what is this...you know.....and then there was an anime called Sword Art Online...It is recent. I like that main guy, it was not a big impact, but he definitely motivated me. Just what happened to the guy and girl was just... It was a good show all around. I watch. Anime not because of all the 
actions, but because of the stories. Just like any other languages, people write stories.” (Alejandro, lines 57-78)

Alvaro also talked about anime and manga in the interview.

"I remember when I was with my[sic] host brother in Japan, and we were with another host sister. She was a bit older and took us driving and showed us around. She took us to coffee shops in uniforms and showed us Manga, and I saw a lot of things that other kids did not. She brought her friends, and we were immersed into Japanese culture.” (Alvaro, 111-115)

Both Alejandro and Alvaro dropped the course in the middle of the semester for unknown reasons.

\section{Games}

Although games were not the first topic the participants talked about when being asked about the reasons and purposes of them wanting to learn Japanese language at FIU, many of the participants reported spending a lot of their spare time playing games. Games here include computer games, Internet games, video games, Nintendo, phone games and TV game shows. Tomas, who was majoring in computer science, when asked about the aspirations of learning Japanese, brought up the topic of Japanese game shows. He said

"Originally, I was looking at the (Japanese) game shows and I thought it was something interesting, and I started to look more at the culture and see how they act and interact with each other. It was something nice. Something new, and something totally different than what I was used to. It was kinda culture shock” (Tomas, lines 47-48). 
Tomas described a career plan involving computers and working for a gaming company (Tomas, lines 99-100). In another interview, Mary also voiced her desire to work for a gaming industry and writing story lines for video games for a company such as Nintendo (Mary, lines 66-67).

It is important to point out that while interests in games did play a role in reasons participants gave for studying Japanese, it was a transitional factor integrated by students into purposes that could be achieved when they are finished with university. This demonstrates how strong a cultural influence games are in their everyday lives and how influential they can be in their career. To put this in perspective, David said that "anime and games are the only two Japanese things” (David, lines 200-202) that he does on a daily basis, and he said that this occupied his spare time completely.

\section{Martial Arts}

According to Erica, who was raised in a small town with a history of racism, there was almost no Asian presence in her town. She explained how she was originally fascinated by Asian culture when “... back in middle school, I wanted to do Marital Arts, and my Mom found this Taekwondo place. I know it is Korean, but when I was there I have met a few other people who were actually into Japanese music and anime and stuff.” She further elaborated.

I: "Were [these people] they around your age?”

Erica: “.......kind of. And we were talking a lot. They have invited me to a convention and stuff which I really did not get into anime scene, but I really liked Japanese Rock music, and their style of music... and then when I hit...it kinda died down in high school, and it came back when I was in college back in... when 
I was working on my liberal arts degree. I had an English class, for my thesis, I decided to concentrate on Japanese culture mainly Samurai and Geisha. My passion .... kind of.... flared up and I wanted to learn more and I started to search what kind of school has that type of study.” (Erica, line 87-95)

For Erica, it was at this martial arts school where she made friends who had similar interests, and was introduced to anime and Japanese music, including J Rock. Since then her curiosity specifically in Japan had grown; recently she completed her AA thesis on Samurai and Geisha from the college that she had attended before attending FIU.

Several students became interested in learning Japanese language because of their interests in different types of martial arts such as Karate, Judo, Taekwondo and many others. Their interests in martial arts in general led them to study Japanese language. This is similar to some students who were not aware of anime and manga being of Japanese origin and later they developed interests in learning the Japanese language.

Daniel and Santiago also practiced martial arts when they were young. Diego who plays Japanese Taiko drums and is a member of Soka Gakkai (religious organization associated with Nichiren Buddhism) currently practices martial arts also. He is the only participant who still practices martial arts. A few other participants have also mentioned their interests in martial arts during the interviews, but do not practice.

Besides anime and manga, games and martial arts, there were other topics that were mentioned in the interviews as a reason of learning Japanese language. For example, both Alvaro and Alejandro mentioned that their girlfriends had influenced them in taking Japanese language. In Alejandro's case, he once had a Korean girlfriend who 
was associated with Japanese religious organization, Soka Gakkai. The researcher asked his reasons and purposes for taking a Japanese language course at FIU and he said that: "Okay, to be honest, in my old high school, I used to date a Korean girl. We broke up, but.... And her religion...her main church... was in Japan.”

I: "What was the religion?"

Alejandro: “I don’t know...”

I: "Possibly, Soka Gakkai.

Alejandro: "Yeah... I think so, but she did not talk too much about it, but I always wanted to go to Japan because of that. She has been there before....... She always told me that it was not really as much of a religion but it was a set of belief of something. This is why I started being interested in Japanese culture... Then, I started to do other things. Right now, she is going to school to be a chef... So... but what she does is she will cook bunch of Japanese food." I: "Is she Korean Japanese?” He stated that his friend was Korean "but she goes to Japan every summer" and that she knows Japanese and only some basic Korean language. It was solely because of this girl that he was interested in Japanese. (Alejandro, lines 200-221)

In Alvaro's case he was interested in a female friend who wanted to participate in a high school summer exchange program in Japan. Because he wanted to spend time with her, so he joined the program. He recounts his experience as follows.

I: "When was the first time you were interested in Japan? ...when you were in high school, right?” 
Alvaro: "Well, when I was in an airplane in Japan......I had no interests in Japan. When I was in high school, this girl Maria I had crush on says, Yo, come with me to Japan and I said I don't know. It is expensive but it was not that expensive. It was like $\$ 2500$ or something. My parents wanted me to go. They wanted me to see the world, so they invested in me. For cost assessment, it was beneficial. Going and seeing different world was... I lived in Kendall, so... Maria was going so my parents felt comfortable. I only went there because I wanted to get with Maria. (Alvaro, lines 190-200)

Alvaro also makes it clear that it was his choice to learn the language.

"It is a requirement [to take Japanese] because I have to take a foreign language course....I could have [taken Spanish] but I felt more comfortable taking Japanese class, because when I went to Japan I did not know any Japanese, You know, I stayed with two host families. They tried so hard to communicate with me. I did not speak Japanese, so they tried so hard to speak to me in English.” He states that it was his choice and that he wanted to learn not for a grade but for himself. (Alvaro, lines 205-212)

These are two male students who originally had no interests in Japan, but they both became acquainted with Japanese culture by chance through their girlfriends and then made a choice to learn a completely new language for themselves.

\section{Utility of Using the Japanese Language}

\section{Study Abroad}

All participants wanted to travel to Japan, at least, if not to live for a short or long term. The researcher asked Alejandro what he thought he would get out of the course. He 
replied that he wanted "to use Japanese eventually to travel. I want to live there maybe six months of my life just to see what is like.” He also said that he was interested in study abroad. (Alejandro, lines 68-72)

Some participants mentioned that they want to see what the country and the culture are like to test them out before committing themselves to live there. However, Santiago was very firm on his plan to study abroad in Japan. (After participating in the interview, he was accepted to study abroad for a year starting fall, 2015.) He said that after studying Japanese for two years in high school he had started to understand the culture. His purpose for studying Japanese language at FIU was quite clearly study abroad. Like Santiago, Mateo described his dream to study abroad in Japan as desire “...for immersion, you know, to be in Japan and...most of the anime fans dream of...also it will force me to learn Japanese. If I am there, I will have to speak in Japanese. Here you are immersed with Spanish and English” (Mateo, line 81).

Erica was interested in FIU Asian Studies and also a study abroad program or exchange program for one year. (Erica, line, 102-111) Sofia was also certain about participating in a semester study abroad program after taking a few classes at FIU. Mary said:

"Well, FIU requires you to take language courses so I was thinking... I took Spanish in high school, so I will just take Spanish again, but then last semester, I have met some exchange students from Japan, Kanda University in Tokyo, and then They became my two close friends. They were very close to me. I, honestly, did not know much about Japan or Japanese until I have met them, but they will tell me about like... cultural differences and language differences and it just 
fascinated me. So, I thought in order to understand them better and be closer to them, I would just like try to learn a little more about their language.”

(Mary, lines 201-220)

Mary was accepted to study abroad for a semester in Japan in 2015.

FIU currently offers two summer study abroad programs, one of which is in Kyoto. Another newly-developed program started in Beppu, Oita in 2015. The latter was created by the researcher herself, which has no requirements for language classes, and is open to all majors at FIU. This was to meet a demand for Japanese culture experiences for students from variety of majors, not necessarily Japanese language. Beside these two summer programs, there are four semester exchange programs. Some participants mentioned that these possible opportunities, along with the variety of Asia-related courses offered are what attracted them to attend FIU.

\section{Employment}

Participants mentioned various types of possible jobs in relation to living in Japan. Diego has vacationed in Japan a few times before and has a clear goal of living in Japan and opening an optical shop in Tokyo. His interview showed specific plans and optimism even if his plan did not work.

Diego: "I heard how much Asian Studies has grown. Honestly... I always wanted to come to FIU, because of Asian Studies, but I guess... I did not think I have a chance since your undergraduate degree has to be correlated to your graduate degree... so I never thought that I have a chance. I thought maybe later in life, I can come to do the Asian Studies"

I: "So now are you an Asian Studies major?" 
Diego: "No, I am actually with the new area studies, Japanese Studies major.” I: “Okay, so you declared the major?”

Diego: "Yes, but I want to do a dual with MA in Asian Studies. After that, I would like to move to Tokyo and have a shop there. It is my current goal. I mean I always wanted to go there. I understand that there is a difference between vacationing in Japan and living in Japan. It is a whole cultural difference. That is why I want to expose myself to as much learning about Japanese culture and everything beforehand, so I can prepare myself and give it a shot, you know. The worst case scenario, I can always come back.” (Diego, line 105-120) Sofia wants to teach in Japan but wants to explore options.

Sofia: "I would like to participate in a study exchange program for summer or a semester, and if I choose to like it really enjoy being there, then I will probably go there to teach English for a year if I can. My goal is to learn different languages, teach, I mean, I already know Spanish, but there is Korean, Chinese and Japanese as well, and the entire continent of Europe.” I: "So it is more job-related that you want to pursue Japanese?" Sofia: "I realize that as a potential, for business... and what I can do with it. So it is not just for interests only. I don't like to do things for interests' sake, I need purposes.”

(Sofia, lines 86-95)

Mateo, whose major is psychology, stated that he would like to find employment in Japan in the field of psychology after graduating from FIU. 
"I guess I am undecided. I can, depends on what branch of psychology I get into. There are for.... As for a bachelor's in psychology, there are not many prospects for me, unless I go into behavioral psychology which, you know, I can immediately attend somewhere dealing with kids with behavioral problems or autism, down syndrome type of things, but other than that I have to go into Master's degree, $\mathrm{PhD}$, and etc. and etc. to actually... It all depends on what path I choose to go into, there are so many branches in psychology... I am also interested in abnormal psychology, personality disorder, schizophrenia...there are also...including paranoia, bipolar many involving psychotic medication, abnormal and behavior... that is my type of interests. I also kind of, I don't know if it is true, I heard that in japan that there are lack of mental health and advancements and you know, maybe sometime in the future, I could be possibly assisting them, you know...(Mateo, lines 58-74)

With only the exception of Daniel, a biology major who was unclear about going to Japan, all the students talked about their future living in Japan, either short or longterm. They have different interests and backgrounds, but all have passion and personal connections with Japanese culture and Japan.

Some parents of participants did not support their children's choice of language. This was never case with the participants' friends. Erica talked about her parents.

Erica: "Everyone has a different opinion. My mom. Whatever decision I make she supports it. My Dad always gives me a hard time about it. He always wanted me to be an engineer. So he has always given me hard time about it.” I: "Does he know that you are taking Japanese classes?” 
Erica: "Yeah, he knows... He said that he did not know why I was taking Japanese class.”

I: "What about Chinese classes?"

Erica: "He would have said the same thing. He is one of those parents that I want you to have this career type of thing. But he said that this is your choice. You have to deal with the consequence"

(Erica, lines 144-156)

I: "You are majoring in Asian Studies in Miami... did your Dad say anything about it?”

Erica: "He did say that. Why Miami? Why are you going so far?”

I: “And Asian Studies in Miami, learning Japanese in Miami.

Erica: "He was more mad that I did not go into Engineering rather than me moving out of Miami.” (Erica, lines 157-163)

The same question was asked to Victoria. She said her parents questioned her choice because “... they were wondering why I was interested in learning a different language. Why not Spanish? Why not Science and Engineering.” (Victoria, lines 198209) Mary talked of her mother's response when she told her that she was taking Japanese this semester, “and she says 'WHY?’” (LAUGH) “She said 'what Made you think to do that?' She was surprised. She was like 'what are you gonna do with that?’ And I said, my best friends are Hanako and Yukiko, and I would love to visit them someday and meet their families and want to communicate with them.” After this answer her mother said 'Okay.... Just work hard'”. (Mary, lines 99-112) 


\section{Inductive Analysis (Phase II)}

The same steps were completed for inductive analysis for Phase II as were done in

Phase I. All remaining students who originally said that they were interested in anime and manga, martial arts and games said that they were still interested in the same activities, and all students indicated increased interest in learning Japanese.

\section{Attraction to Japanese Culture}

\section{Anime and Manga}

Diego talked about his memorable moment as a language learner.

"This is back when I was first really starting learning... in high school years. This is when I absolutely knew that I wanted to go to Japan. I don’t want to necessarily die there, but I want to go there for a couple of years. I was trying to learn Japanese. I will never forget the day. I was with my friends. We were watching Anime in my room, and of course, we prefer to watch Japanese audio with English subtitles, especially back in the days like before 7 years ago. Most American Anime... the translating... they will butcher Japanese. We hated watching in English, and they will also edit the actual film, so we hated that. So I actually understood the complete sentence without having read so... I was like...Oh my god...my friends were like what is wrong, what is wrong... I was like... this is just what he said. My friends were like, Yeah, we all can read the subtitle...NONONONO I did not read that. And they were like .... screw you..., to me it was just the happiest moment.” (Diego, lines 152-164)

After the semester of learning Japanese, Victoria remembered in her L2 learning experiences there were more things that she was influenced by Japanese culture as well as 
anime and manga. They were stories like "1000 Cranes of Sadako" and other things that she learned in school when she was little. She still spends a lot of time watching anime and feels happy that she understands bits and pieces of them without subtitles now (Victoria, lines 82-99).

Most participants mentioned a sense of accomplishment from their learning experience in Phase II as well as feelings of possible future accomplishment. They had started to understand and recognize more and more words, sentences and expressions in Japanese not only in class but also through anime and manga. In many interviews students stated that they wanted to challenge themselves to both learn the difficult language, and to be able to understand anime and manga in the original language. Diego said that there is always "a lost in translation” when it comes to translation that even with the same anime, the original anime and translated anime are different.

When Diego and the researcher were discussing Ideal L2 self, he expressed his idea on "self" using Hello Kitty as an example and said:

"If you look at hugely popular comic character in Japan - hello kitty - hello kitty has a million different versions, but actually if you take a close look at Hello kitty, it has no specific expressions. Sometimes hello kitty are happy. Sometime hello kitty is mad.... It is never shown. It is you. It is your affections and your emotions of how you are feeling. That is what you are projecting on hello kitty. Punk rock and Gothic lolita...or Pretty pink, hello kitty. Whatever it is, that is what you relate to. It is a very intelligent marketing scheme from Sanrio's part. That is why Sanrio is very successful. (Diego, lines 178-187) 
He went on to talk about reliability between oneself and anime character. Susan Napier (2005) described anime are "uncanny evocations of a protean world of imagination that is both unfamiliar and familiar to the viewer, a world of simulations, possible states, and possible identities” (p.293). The early anime attracts Americans with cultural distinction, though contemporary anime has been influenced by Western culture. Speaking of difference between Japanese anime and manga and American anime and manga, Napier asserts that although anime and manga contain "Japanese elements" they are separated from reality even more than are traditional movies. For example, the anime and manga characters are both "Japanese" and "nationless" ."Thus, when a non-Japanese enjoys or identifies with a character, he is identifying within a highly distinctive fantasyscape that combines elements of 'real' Japan within a cartoon imaginary” (Napier, 2007, p. 210).

\section{Martial Arts}

There were still several participants who were fascinated by Japanese martial arts and stated that it was a reason why they were intrigued by Japanese culture and language. Diego was the only participant who currently practiced martial arts. In response to the researcher's question asking about his hobby, he said:

“...we like martial arts. There is another graduate level student who...he and I are practicing martial arts, him more than I am, but he is $9^{\text {th }}$ degree black belt in some karate. So we just started a martial art club and actually trying to make it official in school.... We just had a second meeting. We are meeting every Monday night. We have not made an official name yet. Um.... So anyway, we are helping them (Students/friends) more physically active. James (a class mate in Japanese class) 
and I are actually more active. James is a MMA fighter and he has an official debut. He had a couple of fights before, but he is going to have a fight in January at semi-professional level.”: (Diego, lines 278-288)

\section{Games}

Almost all participants still play games and spend a large amount of time playing various types of games including computer games, Internet games, video games, Nintendo, phone games and TV game shows. Mary said: that "Yeah, I still play video games. Video games are not 100\% Japanese, but I still like them and play games a lot.” (Mary, lines 154-156) Daniel said: "Yes, I play all kinds of games almost every day and watch anime almost every day.” (Daniel, line, 100)

Some participants said that they were excited by the fact that they now understood some words, phrases and written characters in various games after taking one semester of Japanese.

\section{Utility of Using the Japanese Language}

\section{Study Abroad}

Sofia changed her major from Anthropology/Sociology to Asian Studies and she had interests in Korea and China as well as Japan. Victoria also had interests in Korea and China but she said in her Phase II interview that she wanted "to stick with Japanese, because I have learned so much, and I can also do the JET (Japan Exchange and Teaching) program after I graduate.” She said that while she was interested in Korean that “...for Korean, there are not even solid courses for Korean at FIU yet.” 
I: "Let's say if there was, then....? Just like Japanese here at FIU? I think you said before that you would take I: Korean if that was the case before. How about now? Do you feel the same way?”

Sofia: “No, after I have learned so much... “(Sofia, lines 15-20)

Erica became more serious about studying abroad in Japan, however, she first had to convince her Dad.

Erica: “One of my classmates is actually going to study in Japan next semester. She was accepted to Spring semester in Japan.... I am considering for a year-long study abroad in Japan.”

I: "Have you talked to Office of study abroad?"

Erica: "Yes, I talked to them, but I have to talk to my Dad...he is paying for all of this for me.” (Erica, lines 190-200)

Many participants invested money, time and energy for a semester, more so than most expected, and in general confirmed their aim to stick with Japanese language for now and pursue a study abroad for a summer, a semester or a year. A few participants said that the FIU offering of two summer exchange programs and three semester exchange programs was appealing to them in addition to Japanese area studies major and Japanese language and literature. Because of these possible opportunities, some already felt comfortable pursuing their future of learning Japanese language at FIU.

\section{Employment}

Erica, who came to FIU solely to major in Asian Studies, explained that her interests in Japan started in culture but had expanded to Japanese history and language. 
I: "This is your first official language class that you are taking at FIU? Is there any changes on these after you took one semester of Japanese? Is there anything to add? Things have changed? “

Erica: “...before, I was interested in the culture, but I never thought about taking a class in it. And now... I am thinking ... I don’t know how to explain, but.... Now to focus on...Japanese history and culture as well. I don't know if it is separate from the language or together.” (Erica, lines 43-49)

She talked about many possibilities:

"I want to do a lot of things. I think I would like to become a translator and also help teach kids or at a cram school or something like that. Teaching English. I think it is about the same. I think I am more interested in going into like... A historian kind of thing...Well, it is a new development, just a last couple of weeks.” (Erica, lines 149-154)

She was unsure of what she would like to do, but it was clear that, she was exploring her possibilities in terms of future employment after Phase II.

Mateo found other possibilities in relations to Japanese rather than something related to psychology. He was thinking about attending a Japanese university. Mary also discovered other opportunities. "I really have not thought of me doing that (teaching English), but hey I am an English major so you know why not to do something like that.” (Mary, line, 59) She was accepted to study abroad in Japan for a semester in 2015.

Sofia who realized that she liked history as a field of studies during the semester said "I like the fact that history is the history no matter how many times you try it." She said that she always liked history not only from just a historical perspective, but also in 
view of the art and physical representations of things specifically in Asia and Japan. She concluded with, "Not only beautiful things but interesting things in the stories and the reasons for them existing. That to me has been one of the most interesting things...in life pretty much.” (Sofia, lines 150-153) She stated that this field may take her to her future career.

The researcher asked Erica about her future. For Erica, Japanese rock music had been an inspiration in her life.

I: "How do you imagine yourself after the completion of this course as a language leaner? “

Erica: "Hopefully, I see myself like I am talking to other people from overseas and stuff. Actually talking to them, discussing, being able to read....I have whole bunch of magazines that I really want to read.[in Japanese]”

I: "What kind of magazines are they?"

Erica: "Music."

I: "How different is it from Japanese rock to American rock or music?"

Erica: "When I look at lyrics... I love them, Japanese lyrics are more artistic." I: "How do you describe artistic in that sense? Is it in English?"

Erica: “No, it is in Japanese. I read translations.” (Erica, lines 113-130) Erica's vision in terms of Japanese language and culture was vivid. When the researcher asked if she could visualize her using Japanese language in the future- she replied, "I visualize a lot. Every night, I dream about what it is gonna be like when I get my degree.” (Erica, lines 179-180) 


\section{Comparative Inductive Analysis (Phase I and II)}

The sub-themes that were found in Phase I all presented in Phase II. The researcher focused on changes she found by analyzing students' reasons and purposes of taking a Japanese language course at FIU before and after an introductory semester.

Overall, participants’ utility sub-themes, wishing to go to Japan for study abroad or having a job became closer to reality. Culture sub-themes were also still present, with the interests in anime and manga and interest Asia becoming more specific around Japanese culture and games that originate in Japan.

A clear attitudinal change was found in one student, Daniel, who during the Phase I interview, mentioned that he wanted to watch anime without subtitles, yet in the Phase II interview, had a different opinion about studying Japanese language in the future. Although he did not receive a bad grade or change his aspiration to learn Japanese, he came to the realization that it would take years of studying to be fluent in Japanese, and therefore pursued a more limited, short-term goal which was only to fulfill a foreign language requirement. He also stated his major, biology, won’t be able to foster employment opportunities in Japan. He also mentioned that there are not many Japanese natives in Miami.

He talked about this with the researcher in Phase II:

I: “you also mentioned about going to Japan”.

Daniel: "Maybe in the future, but not now...not job-related, because it is very difficult to get a job in Japan.”

I: "Is it fair to say that your interests towards Japanese language, it went down?" Daniel: "A little, yes.... to get a job in Japan is difficult...." 
I: “Okay, what if I just give you a job in Japan starting tomorrow. Would you study more Japanese?”

Daniel: “I guess... Like...... I don’t know.... Well, basic phrases, I guess...living there and working there needs full language. That is why. (Daniel, lines 11-36) I: "So you had expectations of the first class. Did the course meet your expectations?”

Daniel: "Yeah. It was actually easy up until Chapter 4, and it got hard. I think it is grammar. To memorize it...”

I: "why did you decide to take Japanese II if you are not so interested in Japanese like before?”

Daniel: "Oh, because of the requirement for foreign language."

I: "What if there was no language requirement? Let's say if you did not have to take the second class. Would you still have taken it?” Daniel: "I would probably have taken it so that I can finish the first book." I: “... how about level3? ...”

Daniel: "Probably not...If I am Japanese major, I would but.... So, yeah... no.” (Daniel, lines 36-95)

Daniel did not have much initial vision for learning Japanese in Phase I and it decreased in Phase II. When Daniel was asked if he would like to become similar to people who speak Japanese, he said:

"I guess, I want to act like them (Japanese), how they act to other people... ...respect... and all that.....Maturity and all that... how to respect others...”

(Daniel, lines 45-52) 
Daniel was also the only participant who did not mention possible study abroad or visiting Japan near future in the interviews. Even when the researcher asked if he wanted to visit Japan, he was hesitant and said that "not now.” In Phase II, he realized that learning Japanese will take a long time, and with his Biology major it may not be useful for his professional career. He was one of the only two who mentioned about "reading and listening” to place higher importance on speaking.

Erica completed a semester with more options for the future. She saw more of "future possible-selves" in herself. During the first Phase I interview, the researcher found Erica to be very shy and reserved. She said that she was not good at making friends probably due to her family constantly moving around when she was young and did not want to make an effort to make friends if she was going to move anyway. While taking Japanese classes at FIU however, she was able to make close friends in the classroom something she was extremely happy about.

The commitment towards the class from all participants was clear from the beginning perhaps because the course was elective except for all students except the two who were Asian Studies majors. Most of the participants were fluent in the Spanish language and have probably competed Spanish courses with less effort. Comments in the interviews indicated the commitment aspect of the vision of the participants for learning Japanese.

I: "How do you think you will accomplish your goal?"

Alvaro: "Eliminate all the distractions. Getting rid of those people who would come in my way.” (Alvaro, lines 96-100) 
David: "I mean, I already have a commitment, so... the other day, I had to do this homework, just vocabularies and writing and writing and writing. I don't think I have ever sat down and studied like that ever since high school.” I: "Why is that? What about other classes? Engineering classes?" David: "Engineering is usually that you study in class and solve problems." I: “So you don’t have to self-study much?” David: “... no. I guess not. You are doing it during class, but for this, I was sitting almost 2 and a half hours just writing and memorizing...I like that repetitiveness. It was different to me. You look at the book and the book has the answer but you kindda want to look at it. Engineering, that is like.... You solve a problem.” (David, lines 142-151)

When the researcher also asked participants to describe the person they don't want to be like, Mary said:

"I had a friend from Mexico who did not want to speak Spanish." I: “Can she speak Spanish?” Mary: "Yes. Her mom is actually a Spanish teacher. She does not like to speak in public. She would speak to her friends and privately with her mom.” I: "Why do you think that is?" Mary: "I think that for her it was insecurity for being different. You know, beside New York city and Miami, in Kansas, there are certain expectation like you have to speak English to do anything. So I think that.... But she can speak English. So it was more like... I don't want to be ashamed of obviously that I speak English. I 
don't want to be ashamed of learning Japanese...You have to be proud of something.” (Mary, lines 114-125)

Tomas answered the same question:

"There were a couple of people who I used to work with, those colleagues of mine only speak Spanish and did not want to speak in English. They actually helped them to learn English, but they just... why to learn English, we are perfectly fine with just Spanish. ... I don’t want to be like that. I mean...learning a new language will help you. It expands your horizon and gives you more opportunities. More everything.” (Tomas, lines 163-170)

Erica talked about her problem with making friends in general.

I: "I remember you mention that you are not good at making friends."

Erica: "Yeah, when I was younger... I got a lot better since I have been in college. Before, I was very shy and thinking I am not going to make friends since we are moving anyway... but my shyness got stronger so I stopped talking to people in my high school years... but I have met a good friend, Emily, and she is actually the one that got me to Japanese music. And I got more outgoing and started making more friends. I started going to college and talking to people more.” The researcher asked Erica about how she feels about Miami, since she moved from northern part of Florida to Miami recently. She said that "People here are a lot more tolerant. I am kindda from a racist area, and that is not the area that I want to be around. Here it is more diverse.... I feel better here. Much much better.” (Erica, lines 126-132) Diego who seemed vibrant, extraverted and has clear vision in life became close friends with Tomas who has totally different personality but had a somewhat similar 
isolated upbringing; a Spanish speaking Mexican community in Texas for Tomas and a home because of illness for Diego. Despite their obvious differences in personalities, they were able to connect with each other. Diego said:

"I imagine the reason why I am now a great friend with Tomas is... I have asthma and my family has always sheltered me. I was always at home. Very rarely allowed to go out. I had to stay at home and did homework and....and I was little spoiled because I could not go out so my parents thought that oh, let's give him toys and games and... you know. But I did not have many interactions with other people, other kids...” (Diego, line 220-226)

Diego's thought on “relatability" is an important key for this concept. He said: “I guess originally the person's own characteristics that they relate with the characters and that cause them to be interested in Japanese culture. I feel, for instance, people who have whatever they feel like they have to work on themselves, they project that onto a character and when they see that character either getting in lower state or higher state, they can relate themselves and see the potentials in themselves, they reflect that on themselves.” (Diego, lines 230-236) Sofia also spoke about this:

"The funny thing is that I was not little when I saw them (Japanese Movies by Hayao Miyazaki). I fell in love in Japanese culture instantly when I saw that Kiki delivery movie. I knew it was not a Japanese culture, but it was coming from the mind of a man that has Japanese culture and you could tell that it was not Westernized movie. They tried very hard, but the key components were Japanese and they were just beautifully put. So, the reason why I am interested in learning 
Japanese was that I always wanted to go and experience different cultures from myself and figure out just how similar and how different they were from mine.” (Sofia, lines 47-51)

\section{Three Emergent Themes (Phase II)}

In Phase II, three additional themes emerged. They were a sense of community, the investment of time, and openness to others.

\section{Sense of Community}

Erica and several other participants indicated that they have made new close friends in the Japanese class who shared similar interests and continue to take classes together. In a similar vein, Diego touched on the topic of Japanese classes and this sense of community by saying “..... we have built a sense of community (in class) and we support each other. Often time before the class we will get together especially before the test, we will actually get together and help each other, so we feel like we grow together and we all are dedicated...” (Diego, line 24) This sense of community was built among most of the participants during the semester, including the relationship with the instructor. This was very meaningful for those students who described themselves as shy and also students who just moved to Miami.

\section{Investment of Time}

Some of the students who were interested in other Asian languages, such as Chinese and Korean, stated that they had invested so much time for learning Japanese language that they wanted to continue with Japanese. Victoria said that students, from the beginning, want to know that they can continue studying the language with various levels. In her interview she was asked: 
I: "Now that you have taken one course of Japanese language course at FIU, how have the purposes and reasons of you taking Japanese changed? ...”

Victoria: "I want to stick with Japanese, because I have learned so much, and I can also do the JET program after I graduate.”

I: "Why did you think that Japanese is more for you than Korean? You want to do JET?”

Victoria: "Because for Korean, there is not even solid courses for Korean yet." I: "Let’s say if there was, then....? Just like Japanese here at FIU? I think you said before that you would take Korean if that was the case before. How about now? Do you feel the same way?”

Victoria: "No, after I have learned so much..."

I: "You invested so much time for it?"

Victoria: "Yes. I have learned so much and I now understand hiragana chart. I am weak in Katakana, writing style for foreign words, still” (Victoria, lines14-23)

There were several participants who said they enjoyed the course tremendously, and that it exceeded their expectations although they had to spend quite a lot of time on the course. One of those participants was Sofia:

I: Did anything evolve from the experience?

Sofia: I did not think I would enjoy it as much as I did... I loved it, actually. Actually, I made more friends and met more friends that are same mind-set as me.”

I: "Define your mind-set, please". 
Sofia: "Ummm.... trying to be open to new things and seeing different ways of life... like culture.....and not only like Japanese but also, you know, I mean, yesterday me and my group went to eat Korean food for the first time because none of us has tried it before. And, you know, we all loved it.” (Sofia, lines 2536)

Among the 10 participants of Phase II, all mentioned that the basic reasons and purposes of learning Japanese language at FIU did not change much after a semester of official learning at FIU. For example, Diego responded that "My major reasons and purposes of learning Japanese.... It is still overall the same. To be able to live and work in Japan... and that has not changed at all.” (Diego, lines 54). Mary thought that she learned a lot more that she thought she would in one semester and also said that her purposes and reasons for learning Japanese language, mainly to meet with Japanese friends in Japan again, are still exactly the same.

\section{Openness to others}

Daniel and Tomas placed "reading and listening" higher in importance over speaking in language learning. Both were extremely quiet and extremely shy in Phase I. However, in Phase II, the researcher found that both Daniel and Tomas felt comfortable speaking with her. Tomas talked about his new curiosities in the world and explained about his upbringing which did not allow him to explore his surroundings and life itself. He said he would like to travel all over the world, and he is ready now especially after making a few close friends in Japanese class. He also thought that being able to speak in the language is important. Daniel mentioned that he finds his possibilities in life though 
anime with his close friends whom he mentioned that are closest in his relationship over his own parents.

Overall, the findings for Phase II were similar to the findings for Phase I except for one participant as previously presented. However, there were three new emerging themes that affected participants' motivation related to continuing of Japanese language study after L2 experience: sense of community, openness to others, and investment of time. Also, it can be said the L2 experience affected participants' motivational level mostly positively but also negatively. Nine out of 10 students clearly confirmed their original purposes for studying Japanese at FIU. In relationship to L2, among 3 dimensions of L2 motivational self- system, L2 ideal-self and L2 learning experience had the most influence on participants' motivational level and possible selves, mostly positive. Also, regardless of increase and decrease in envisioning future-selves in relation to Japan, the finding was that just one semester of learning experience, along with L2 experience in context, influenced their motivations and future visions tremendously. Lastly, methodologically, the keeping and using of reflective journals not only enabled the researcher to make her experiences, opinions, concerns, feelings, thoughts visual but also helped organize collected data. 


\section{CHAPTER V}

\section{DISCUSSION AND RECOMMENDATIONS}

This chapter is divided into six sections. They are response to the research question, reflections through the lens of L2 motivational self-system, recommendations for further research, recommendations for practice, summary, and a conclusion.

\section{Response to Research Question}

The research question was: What are the non-Japanese undergraduate students' reasons and purposes for taking a beginner's Japanese language course at Florida International University?

The researcher found that the reasons and purposes of the participant for learning the Japanese language generally started with curiosity in, attraction to, fascination with and romanticizing about a language and culture that is different from their own language and culture, which in most cases, was of Hispanic or American origins. Ten of the twelve participants were bilingual in English and Spanish. Their backgrounds varied from Ecuador, Honduras, Mexico, Nicaragua, Peru, the Philippines, Puerto Rico to the United States which is typical for the unique setting of Miami and Florida International University. One of the non-speaking Spanish participants spoke Tagalog as a native language spoken in the Philippines.

Through thematic inductive analysis, the researcher found two major themes that emerged from the collected data: attraction to Japanese culture and the utility of using the Japanese language.

The culture theme included the sub-themes of anime and manga, martial arts and games (computer games, Internet games, video games, Nintendo, phone games and TV 
game shows). Among these, anime and manga was the most influential reason for developing an interest in learning Japanese language and culture. The second major theme, the utility had two sub-themes. These were study abroad and employment, both requiring residence in Japan.

It is important to point out that while interests in games did play a role in reasons for studying Japanese, it was a transitional factor integrated by students into purposes that can be achieved when they are finished with university. The clear delineation between "reasons" and "purposes" here was that the latter is a broader concept to be, "achieved when they were finished with university” while the former was an immediate driver.

Watching anime and reading manga as well as playing variety of games or watching games were part of the participants' lives. Anime and manga became their hobbies that continued into Phase II. The fact that only one participant still practices martial arts and also the fact that they did not talk much about it in Phase II made the researcher postulate that perhaps martial arts took a role as a starting point of the participants being interested in Asia in general and they then developed particular interests in Japanese culture and language at a later time.

According to Fukunaga (2006) there has been a shift in motivations of Japanese learners in U.S. Japanese learners' reasons and purposes for learning Japanese which used to be business-oriented. Manes (2005) indicated that today’s younger generation gain knowledge and information on Japan especially Japanese pop culture. through the Internet She observes that a younger generation who grew up with J-pop develop serious interests in anime and manga which leads them to have interests in learning the Japanese language. This view is parallel to the researcher's findings. Table 3 shows the most 
common motivations for studying the Japanese language amongst overseas students as found in The Japan Foundation's 2012 survey.

Table 3.

Motivation for Japanese Language Study in Overseas Students:

Motivation Percentage

Interest in Japanese language $\quad 62.2$

Communication in Japanese $\quad 55.5$

Interest in manga, anime, J-pop, etc $\quad 54.0$

Interest in history, literature, etc $\quad 49.7$

For this most recent 2012 world-wide survey by the Japan Foundation, the item for "Interest in manga, anime, J-pop, etc.” was newly added for a choice to select from as a reasons and purposes of Japanese study. Similarly, findings of the current study revealed participants' interests are heavily involved with Japanese pop culture (J-pop) which includes anime and manga, music, cinema, cuisine, and television programs. It is also evident that traditional/ancient Japan such as Samurai, Geisha, History, traditional music and art have attracted students, but not to extent of interests that the study found in J-pop. It seems that cultural elements (ancient or modern) of Japan were students' reasons for learning Japanese language. Once the students became immersed in their language study, they developed more concrete practical purposes for its use. The students articulated these purposes as participating in a study abroad program in Japan and getting a job in Japan. 


\section{Reflections through L2 motivational self-system}

The following section is the researcher's interpretation of the findings seen through the lens of the theoretical framework used in this study, L2 motivational selfsystem. It attempts to explore connections between L2 motivational self-system and the findings. Among the three dimensions of the system, the researcher found a close link between the findings a) Ideal L2 Self and b) L2 learning experiences.

\section{Ideal L2 Self \& Culture theme and Utility theme}

The ideal L2 self is based on the individual's aspirations and goals as a language learner and refers to "the representation of the attributes that one would ideally like to possess (i.e. representation of hopes, aspirations, or wishes)” (Dörnyei, 2009, p.13). It is “a powerful motivator to learn the L2 because of the desire to reduce the discrepancy between our actual and ideal selves” (Dörnyei, 2009, p.29). Especially with anime and manga, many participants visualized themselves understanding anime and manga in the original language, Japanese instead of reading subtitles. According to some participants, understanding anime and manga in the original language makes them feel closer to the content. In addition, some participants explained that they often see lost in translation segments in anime and manga that they watch outside of Japan and anime and manga in Japanese. For example, it is hard to find direct translations for certain words from Japanese to English and vice versa, curse words, for example. Even if there is a line such as “I love you.” in English, Japanese translation will be slightly different from a literal translation. Also, there are some visual restrictions for anime and manga when they go out of Japan. 
Thus, many students who have serious interests in anime and manga often gain aspirations and goals for learning Japanese language by hoping to understand them in the original Japanese language.

Today's anime welcomes transnational audience who can find his/her own space and identity in a big campus of anime (Napia, 2007). It is anime and manga, many students seemed to wish for a place to belong. Daniel who spends a large amount of time watching Japanese anime daily along with other participants think that American heroes tend to be strong and tough, but many of Japanese anime characters are small, not so strong, rather vulnerable but become strong. Anime and manga give messages about life to the audience in the process. Several participants mentioned that whenever they have had hardship in life, watching anime and reading manga has helped them overcome their struggles. Anime and manga motivates and stimulates them to go on. In the present study, many research participants seemed to search their identity though anime and manga. The participants often discussed about the characteristics of main characters in anime and manga that were more personable and relatable than individuals in real life. Applying this to the curriculum design, making classes "personable and relatable" to the students seem extremely important. To make classes personable, teachers' skills are required. Creating a micro and macro community is important. Making students with different personalities feel comfortable and have them see their own potentials with the language in and outside of class is also important.

It was clear to the researcher that the vision of itself was a powerful motivator to learn, and also to continue learning the language. The findings of similar study conducted by Barbara Northwood (2013) investigating persistence and learning Japanese in a 
particular high school and university in Australia that included the link between persistence and a developing sense of self-identity as a Japanese speaker among advanced learners. These findings also tie in with Dörnyei’s (2009) concept of language identity and the L2 Self. Northwood's (2013) findings also showed that the motivation of J-pop means more to the students that give inherent enjoyment, and some students are seeking for self-identity through it. With the researcher's understanding of motivation as a dynamic entity that evolves over time (Hsieh, 2009), notions of ideal L2 self (Dörnyei, 2005, 2009) were useful in this study. For example, it was understandable to find Daniel's lack of motivation to continue learning Japanese in Phase II, and his lack of a future Japanese speaking self. Even in the Phase I interview with Daniel, there were predictable signs of lack of ideal L2 motivational self-system demonstrated by Daniel such as a lack of confidence and overall skepticism about his Japanese learning in the future, which may relate to his vision of future-self related to Japan among all of them. As Daniel was the only participant who did not see himself studying abroad or living in Japan and because "the more vivid and elaborate the possible self, the more motivationally effective it is expected to be” (Dörnyei, 2005, p. 100), it was not surprising that his motivation decreased tremendously after a semester of learning Japanese. Viewing L2 motivation as Dörnyei proposes, as the L2 motivational selfsystem, several students were successfully developing a Japanese speaking identity through L2 learning experience as a speaker of Japanese during the semester.

Aside from Daniel, all nine students were inspired and their interests in Japan clearly increased in Phase II. They visualize more clearly themselves going to and living 
in Japan. All other participants' purposes, except Daniel's, were strongly affirmed after L2 experience.

Following are words and phrases of the participants that were used after being asked about what would be required to be a successful language learner.

-Willing to adopt and also willing to learn the language.

-Participating in all the activities in class.

-Patience

-Practice

-Open-minded

-Know the foundation

-You have to study hard.

-Confidence

-Dedication

-Tons of studying.

-You have to put time for it.

-You have to be on top of what you are doing.

-Meeting all the obligations, consistency and having fun.

-Perseverance

-Self-motivation

Taken together, this list of utility theme, after one semester of learning experience, students' vision of their future-self included a variety of career and noncareer options. Some of the career options were: teaching English in Japan, starting an optical store in Japan, translations, working for game industry, writing story lines for 
game company and etc. Non-career options were: changing a major to Japan-related major, studying in Japan, visiting friends in Japan and etc. Especially in Phase II, most students clearly visualized themselves in these positions.

In sum, most participants described themselves as successful users of Japanese language in the future. Even when the researcher asked negative questions such as "What if you fail the class?”, they answered with a positive outcome. There were some participants who had very specific goals in Japan, and a few participants that had nonspecific goals, yet all were highly motivated in pursuing Japanese to help lead them to Japan.

\section{L2 learning experience \& Culture theme and Utility theme}

L2 Learning Experience, which concerns situated, 'executive’ motives related to the immediate learning environment and experience (e.g. the impact of the teacher, the curriculum, the peer group, the experience of success). (Dörnyei, 2009) (p. 29)

This dimension has close links with how L2 learners can be influenced by immediate learning environment and experience such as the curriculum, the L2 teacher, the peer group, and the teacher materials, the experience of success (Dörnyei, 2005, 2009). In this study, the L2 learning experience and the ideal L2 self showed significant impact on motivating behavior and were well-connected to the findings' main themes. The researcher categorized next part into two sections since there were two significant the striking points that were used in the diagram presented at the end of this chapter since they were well-connected to L2 learning experience. They were (a) importance of teachers and peer group and (b) confidence from the L2 learning experience. 


\section{Importance of Teachers and Peer group}

Learning experience is important to continue learning the subject. All participants spoke about the importance of classmates and instructors during learning experience.

Alvero in Phase I, talked about his impression of his teacher and peers as "My teacher is so kind. My first impression is that he is very helpful, nice and ...easy to communicate with....My peers in classroom, they seemd very nice and care for people. They seem like they are completely interested in the calss and they like to be in that community, so if I talk to them, communicate with them, be friends with them, it will help me out.” (Alvero, lines 89-96) Sofia who changed her major from Anthropology/Sociology to Asian Studies attributes her reason for this to the fact that she could not get along with people in her major classes. Sofia and Erica also talked about how much they enjoyed learning the new language with new friends who have similar interests despite the fact that they had to spend so much time studying for the course.

Many participants had interests in Japanese pop culture. They expressed how easy and fun it is to study with classmates who have same interests, in this case anime, manga and games and similar future goals such as studying abroad and working in Japan.

Going back to importance of peer group, anime and manga become their intense hobbies that intrigue people who have similar interests and create their own community. From the interviews with the participants, it seemed that collective nature of Japanese culture made it easier for the participants to build its own community in Japanese classes and the instructor took a leadership role in creating such a community. Specific characteristics of Japanese people such as groupism, verticality (Nakane, 1970) and 
dependence (other directedness) (Doi, 1973) may be related to this phenomenon among students. Some said that they made best friends in Japanese class and also wanted to take classes with the same classmates for next level. It matters to them who they study with.

On the topic of instructors, many participants confirmed the importance of the instructor's role inside and outside of the classroom. Alejandro referred to an earlier experience on this topic.

I: "When did you study German and why?"

Alejandro: "Because in high school, we had to take 2 years of foreign languages, and in my high school there was Spanish which I already know how to write and speak it, and there were French or German. I chose German...I enjoy studying different languages, but for German, Id di not really like it.” I: "Why was that?"

Alejandro: "Well, you know, you get to know the culture, and the culture, I did not like. Their culture was not what I expected it to be. Also, one day, I had to make a presentation in front of everyone, and I realized at the end that I was just speaking in one tense. I did not use any past tense or... It was very embarrassing ... the teacher called me out. It was not that everyone had it down, so it was not too bad, but it was embarrassing. I was so confident so... It hurt.” (Alejandro, lines 230-253)

All the students from the interviews confirmed that their Japanese instructors at FIU did excellent work and all participants talked highly of all of their instructors. Mary said that the even if the subject seems a boring one, an instructor can make the class intriguing and fun. All participants said that the instructors created a comfortable setting, 
and made a class challenging, they gave individual base instructions that it was not just memorization and most of all it was fun. "It is all about the teacher. You know I have taken classes that I thought the subjects are awesome and the professor was awful and it made me lose my interests in the subject. (Mary, lines 117-125) Most importantly, the participants said that instructors introduced Japanese culture through the Japanese language in class.

\section{Confidence from the L2 Learning Experience}

As a result of the experience of this language learning, the confidence level went up for many students which was in turn related to the motivation level to continue learning the language. Erica, for example, said that this learning experience made her realize that she can do more in life than being in Florida because she met classmates who are from all over the world. Simply just taking one semester of Japanese class motivated her to seek other possibilities in relation to Japan. It gave her a free way to talk to people. For someone who comes from a small town, just to be in a Japanese language class in Miami was an eye-opening experience. Diego also gained confidence. He said that the learning experience

“.... fueled my desire to increase my knowledge and language proficiency. And through the course...I gained my confidence ... maybe my potential... maybe it is higher level that I thought... like before I was a little afraid like what if I cannot do this, I mean I was gonna give a shot, and give best, but what if I am not able to become fluent. Like I said, I don't feel fluent in any way yet, but I feel that I have the ability and chance to become fluent.” (Diego, line 94)

Not only did Diego gain confidence about language efficiency but also about himself. 
Experience of successful learning and success in classroom brings the students' confidence level up as indicated in the previous interviews, thus, their utility themes, employment and study abroad, in relations to Japan became more realistic than before.

\section{Recommendations for Future Research}

The uniqueness of the student body, background of the research site, and what the host institution can or would like to offer (such as a major, minor, certificate and school curriculum) has to be included in consideration when it comes to research related to language learning motivations. The setting of this particular research was unique. FIU has many bilingual Hispanic students. It would be worthwhile to conduct this same research in another location with different characteristics other than those of the research setting.

Also, the research focus on beginner's Japanese language courses; however, students' reasons and purposes for studying Japanese language may differ depending on their language level, therefore, future qualitative research exploring differences and also changes on their reasons and purposes depending on their levels will be recommended. Future research may also explore how the motivations and motivational influence their language learning outcome.

\section{Recommendations for Practice}

The reasons and purposes of non-Japanese undergraduate students taking a beginners' language at FIU can be categorized in two themes, attraction to Japanese culture and the utility of using the language. Attraction to Japanese culture includes anime and manga, martial arts and games (computer games, Internet games, video games, Nintendo, phone games and TV game shows). Utility of using Japanese language includes study abroad and employment in Japan. This research finding ties to 
competency-based learning goals of the Japan Foundation. The Japan Foundation developed JF (Japan Foundation) standard to help Japanese teaching and learning. Their assessment system is unique. Based on their standard, a Japanese learner's proficiency is measured by what the learner "can do" in Japanese as the necessary situation arises in a specific context. This practical measurement is nothing like the traditional way of assessment which simply divide "beginner" "Intermediate" or "advanced" that rely on memorization of grammars, vocabularies, and coverage of textbooks. Since these "cando" statements that the Japan Foundation has proposed specifically describe themes and learning goals. This communicative competence is needed in real life which ties to the finding of the research. Most of the students want to live in Japan for study abroad or employment. Moreover, tying to the theoretical framework, L2 motivational self-system, clarifying learning objectives using "can-do" statements will help students to have vision for each class and long term vision as a Japanese language learner.

This finding might be used by policy makers or curriculum developers to refine or enhance or strengthen the competency goals. Utilizing teaching materials related to anime, manga and traditional and modern Japanese culture instead of using written textbased materials may be appealing to students. As simple as it may sound, the language learning needs to be "fun" and "enjoyable" and create a community as many participants mentioned.

Developing such curriculum will take time, energy and articulation among teachers at the institution and professional network locally and nationwide, but can be meaningful. 


\section{Summary}

The reasons and purposes of non-Japanese undergraduate students taking a beginners' language at FIU can be categorized in two themes, attraction to Japanese culture and the utility of using the Japanese language. Attraction to Japanese culture includes anime and manga, martial arts and games (computer games, Internet games, video games, Nintendo, phone games and TV game shows). Utility of using the Japanese language includes study abroad and employment in Japan. There were three emerging themes in Phase II that were sense of community, openness to others, and investment of time.

Findings were also analyzed through the lenses of L2 motivational self-system.. The researcher found that L2 ideal-self and L2 learning experience were most connected with the findings and interpreted that there were two key components related to L2 learning experience. They were (a) importance of teachers and peer group and (b) confidence gained from the L2 learning experience.

Overall, participants were generally influenced by anime, manga and martial arts in that they were exposed to it when they were young. The interests in Asia in many cases developed into interests in Japan, in particular at the later time.

Games (computer games, Internet games, video games, Nintendo, phone games and TV game shows) also indirectly influenced the participants. Games are something that they do in their spare time. Since many Japanese companies produce variety of games, some participants developed interests in working for gaming companies. Almost all participants gained L2 confidence with and through teachers and peer group, and resulted in successful learning. Successful L2 learning experience helped participants to 
see themselves and to see their potentials in general beyond their potential to learn Japanese language, and for study abroad and employment in Japan to be specific. Reasons are integrated into purposes.

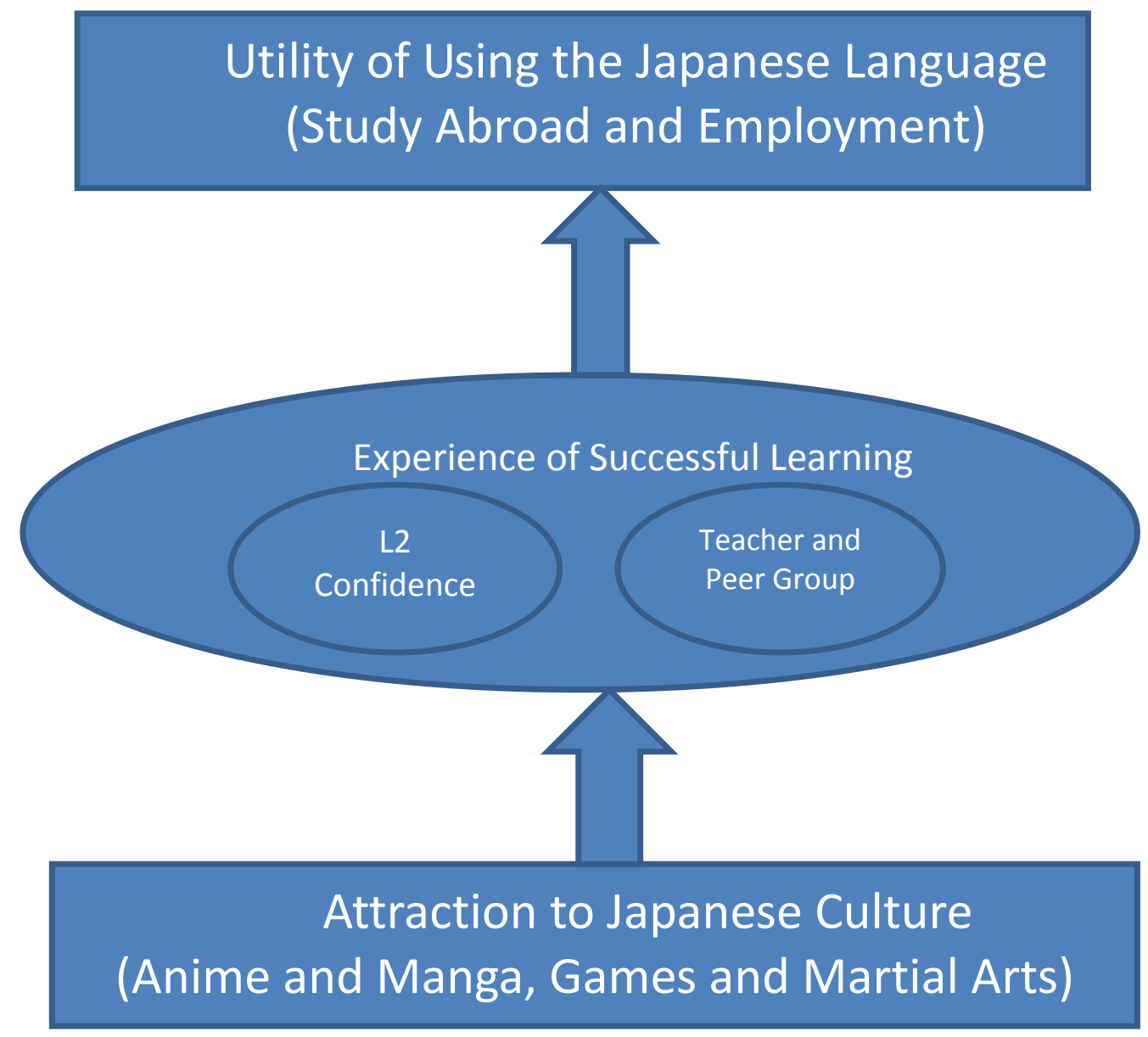

Figure 3. Summary of Findings.

\section{Conclusion}

The instructors can testify that students' motivation fluctuate throughout a lesson, a day and over a far longer period of time. It takes as much effort to motivate students to learn as it takes to keep them motivated for a measurable academic improvement. An inspiring L2 future vision will most likely override these fluctuations and keep students focused on their L2 goal. From the findings, L2 motivational self-system’s "L2 ideal- 
self" and "L2 learning experience," in particular, seems to help students clarify and connect their L2 inspiring vision with their L2 leaning experience.

By creating a personally relevant and inspiring vision of possible-future L2 self, the student may be inherently motivated which then allows the instructor to be more productive and effective in their teaching. Thus, using L2 motivational self-system approach in teaching and learning allows for better stability in classroom setting. Creating such positive future visions among students from the beginning of the course will be beneficial for successful L2 acquisition. 


\section{REFERENCES}

Ahern, K. J. (1999). 'Pearls, pith, and provocation: Ten tips for reflexive Bracketing', Qualitative Health Research 9(3), 407-11.

Altrichter, H., Feldman, A., Posch, P. \& Somekh, B. (2008). Teachers investigate their work; An introduction to action research across the professions ( $2^{\text {nd }}$ ed.). Routledge.

“anime.” Merriam-Webster. (2015). In Merriam-Webster.com.Retrieved April 13, 2015, from http://www.merriam-webster.com/dictionary/anime

Association of the United States Army. (2010, August). DLI's language guidelines. AUSA Special Reports. Retrieved from:

http://www.ausa.org/publications/ausanews/specialreports/2010/8/Pages/DLI\%E2\%80\%9 9slanguageguidelines.aspx

Bakar, K. A., Sulaiman, N. F., \& Rafaai, Z. A. M. (2010). Self determination theory and motivational orientations of Arabic learners: A principal component analysis. GEMA: Online Journal of Language Studies, 10(1), 71-86.

Bogdan, R. C., \& Biklen, S. K. (2003). Qualitative research for education: An introduction to theories and methods ( $4^{\text {th }}$ ed.). New York, NY: Pearson.

Bogdan, R.C. \& Biklen, S. K. (2006). Qualitative research for education: An introduction to theory and methods (5th ed). Needham Heights, MA: Allyn \& Bacon.

Bradshaw, Jim. (2006, Oct. 13). 12.9 Million in Grants Awarded for CriticalForeign Language Instruction. U.S. Department of Education. Retrieved from:http://www.ed.gov/news/pressreleases/2006/10/10132006a.html

Boyatzis, R. E., \& Akrivou, K. (2006). The ideal self as the driver of intentional change. Journal of Management Development, 25(7), 624-642.

Chen, S. (2012). Motivation and Possible Selves: An Interview Study of Taiwanese EFL Learners1. Language Education in Asia, 3(1), 50-59.

Clément, R., Dörnyei, Z., \& Noels, K. A. (1994). Motivation, self-confidence, and group cohesion in the foreign language classroom. Language learning, 44(3), 417-448.

Crookes, G., \& Schmidt R. W. (1991). Motivation: Reopening the research agenda. Language Learning, 41(4), 469-512.

Deci, E. L., \& Ryan, R. M. (1991, January). A motivational approach to self: Integration in personality. In Nebraska symposium on motivation (Vol. 38, pp. 237-288). 
Deci, E. L., \& Ryan, R. M. (2000). The" what" and" why" of goal pursuits: Human needs and the self-determination of behavior. Psychological inquiry, 11(4), 227-268.

Dobuzinskis, A. (2011, April 21). More U.S. Students Learning Chinese As School Language Programs Expand. The Huffington Post. Retrieved from: http://www.huffingtonpost.com/2011/04/21/more-us-studentslearning_n_852093.html

Doi, T. (1973). The anatomy ofdependence. Trans. John Bester. Tokyo: Kodansha International.

Dörnyei, Z. (1990). Conceptualizing Motivation in Foreign-Language Learning*. Language learning, 40(1), 45-78.

Dörnyei, Z. (1994). Motivation and motivating in the foreign language classroom. The modern language journal, 78(3), 273-284.

Dörnyei, Z. (1998). Motivation in second and foreign language learning. Language teaching, 31(03), 117-135.

Dörnyei, Z. (2001). New themes and approaches in second language motivation research. Annual Review of Applied Linguistics, 21, 43-59.

Dörnyei, Z. (2002). The motivational basis of language learning tasks. Individual differences in second language acquisition, 137-158.

Dörnyei, Z. (2005). The psychology of the language learner: Individual differences in second language acquisition. Mahwah, NJ: Lawrence Erlbaum.

Dörnyei, Z. (2009). The L2 motivational self-system. Motivation, language identity and the L2 self, 9-42.

Dörnyei, Z., \& Csizér, K. (2002). Some dynamics of language attitudes and motivation: Results of a longitudinal nationwide survey. Applied Linguistics, 23, 421-462.

Dörnyei, Z., \& Ottó, I. (1998). Motivation in action: A process model of L2 motivation. Working Papers in Applied Linguistics (Thames Valley University, London), 4, 43-69.

Dörnyei, Z., \& Ushioda, E. (Eds.). (2009). Motivation, language identity and the L2 self (Vol. 36). Multilingual Matters.

Dörnyei, Z., \& Ushioda, E. (2013). Teaching and researching: Motivation. Routledge.

Ely, C. M. (1986). Language learning motivation: a descriptive and causal analysis. The Modern Language Journal,70 (1), 28-35. 
Finston, M., \& Aurigemma, M. (8 December 2010). New MLA Survey Report Finds That The Study Of Languages Other Than English Is Growing And Diversifying At US Colleges And Universities', Modern Language Association. Retrieved from: http://www.mla.org/pdf/2009_enrollment_survey_pr.pdf

Florida International University. (2014). About FIU. Retrieved from http://www.fiu.edu/about-us/rankings-facts/index.html

Fukunaga, N. (2006). “Those anime students”: Foreign language literacy development through Japanese popular culture. Journal of Adolescent \& Adult Literacy, 50, 206-222.

Furman, N., Goldberg, D., \& Lusin, N. (2010, December). Enrollments in Languages Other than English in United States Institutions of Higher Education, Fall 2009. In Modern Language Association. Modern Language Association. 26 Broadway 3rd Floor, New York, NY 10004-1789.

Gardner, R. (1985). Social psychology and second language learning: The role of attitudes and motivation. London: Edward Arnold.

Gardner, R. C. (2001). Language Learning Motivation: The Student, the Teacher, and the Researcher. Texas Papers in Foreign Language Education, 6(1), 1-18.

Gardner, R. C., \& Lambert, W. E. (1959). Motivational variables in second-language acquisition. Canadian Journal of Psychology/Revue canadienne de psychologie, 13(4), 266.

Gardner, R. C., \& Lambert, W. E. (1972). Attitudes and motivation in second language learning. Rowley, MA: Newbury House.

Gardner, R. C., \& Tremblay, P. F. (1994). On Motivation, Research Agendas, and Theoretical Frameworks1. The Modern Language Journal, 78(3), 359-368. Ivankova

Gorden, L. (2010, December 7). Arabic, Korean and Chinese deemed fastest-growing language courses at U.S. colleges. Los Angeles Times. Retrieved from: http://articles.latimes.com/2010/dec/07/nation/la-na-college-languages-20101208.

Guest, G., Bunce, A., \& Johnson, L. (2006). How many interviews are enough? An experiment with data saturation and variability. Field methods, 18(1), 59-82.

Higgins, E. T. (1987). Self-discrepancy: a theory relating self and affect. Psychological review, 94(3), 319.

Hsieh, C. N. (2009). L2 Learners' Self-Appraisal of Motivational Changes OverTime. Issues in Applied Linguistics, 17(1). 
Hudson, G. (2000). Essential introductory linguistics. Blackwell Publishers.

Isoyama M. and Lin, T. (2006). Survey report on Japanese language education abroad 2006. Breeze, 35. Retrieved from: http://www.jflalc.org/pub-breeze35.html

Iuspa, F. E. (2010). Assessing the Effectiveness of the Internationalization Process in Higher Education Institutions: A Case Study of Florida International University.

Jae-Un, Limb. 2012. Psy's Popularity Gives A Boost To Korean Language. Retrieved from: http://www.korea.net/NewsFocus/Culture/view?articleId=102801

Johnson, B., \& Christensen, L. (2004). Educational research: Quantitative, qualitative,and mixed methods (2nd ed.). Boston, MA: Pearson Education.

Johnson, M., \& Johnson, Y. (2010). An exploratory study of Japanese engineering students' EFL learning motivation. 北海道言語文化研究, (8), 43-56.

Jorden, E. H., \& Lambert, R. D. (1991). Japanese Language Instruction in the United States:Resources, Practice, and Investment Strategy. National Foreign Language CenterMonograph Series.

“J-pop Music Genre.” The Music Genre’s List (2010-2015). Retrieved from http://www.musicgenreslist.com/music-j-pop/.

Koebler, J. (2012). Education Funding for Foreign Languages Cut. Retrieved From: http://www.usnews.com/education/blogs/high-schoolnotes/2012/01/16/education-funding-for-foreign-languages-cut

Kvale, S. (1996). Interviews: An introduction to qualitative research interviewing. Thousand Oaks, CA: Sage.

“L2.” Glossary of TEFL Acronyms (2002-2012). (2015, October 12). Retrieved from http://www.teaching-english-in-japan.net/acronyms/l2.

Lin, T. (2006). How to save your Japanese Language Program. Breeze, 35. Retrieved from: http://www.jflalc.org/pub-breeze35.html

Manes, K. (2005). Anime gives U.S. students window on Japan. Retrieved April 26, 2005, from http://www.yomiuri.co.jp/newse/20050426wob3.html

“Manga.” Merriam-Webster. (2015). In Merriam-Webster.com. Retrieved April 13, 2015, from http://www.merriam-webster.com/dictionary/manga

Markus, H., \& Nurius, P. (1986). Possible selves. American psychologist, 41(9), 954.

Maxwell, J.A. (1996). Qualitative Research Design: An Interactive Approach. Thousand Oaks, CA: Sage 
Merriam, S. B. (1998). Qualitative research and case study application in education. San Francisco, CA: Jossey -Bass

Merriam, S. \& Simpson, E. (1995) A Guide to Research for Educators and Trainers of Adults, FL: Krieger

Moiinvaziri, M. (2008, December). Motivational orientation in English language learning: A study of Iranian undergraduate students. In Global practices of language teaching: Proceedings of the 2008 International Online Language Conference (pp. 126-136).

Motivation. 2014. In Psychology Dictionary. Retrieved from http://psychologydictionary.org/motivation/

Oxford, R. L., \& Shearin, J. (1994). Language learning motivation: expanding the Theoretical framework. The Modern Language Journal. 78(1), 12-28.

Oxford, R. L., \& Shearin, J. (1996). Language learning motivation in a new key. In R.L. Oxford (Ed.), Language learning motivation: Pathways to new century (pp. 121144). Honolulu: University of Hawai'i, Second Language Teaching and Curriculum Center.

Patton, M. Q. (2002). Qualitative research and evaluation methods (3rd ed.). Thousand Oaks, CA: Sage.

Peshkin, A. (1988). In search of subjectivity—one's own. Educational Researcher, 17(7), $17-21$

Purpose. 2014. In Psychology Dictionary. Retrieved from http://psychologydictionary.org/purpose/

Reason. 2014. In Psychology Dictionary. Retrieved from: http://psychologydictionary.org/reason/

Ryan, G. W., \& Bernard, H. R. (2003). Techniques to identify themes. Field methods, 15(1), 85-109.

Ryan, R. M., \& Deci, E. L. (2000). Self-determination theory and the facilitation of intrinsic motivation, social development, and well-being. American psychologist, 55(1), 68.

Ryan, R. M., \& Deci, E. L. (2003). On assimilating identities to the self: A selfDetermination theory perspective on internalization and integrity within cultures. Handbook of self and identity, 253-272. 
Ruch, G. (2011). Japanese Language Classes at US Colleges are More Popular than Chinese and Korean Combined. Asian Matters For America. Retrieved from: http://www.asiamattersforamerica.org/japan/japanese-language

Rubin, H.J., \& Rubin. I.S. (2005). Qualitative interviewing. The art of hearing data (2 ${ }^{\text {nd }}$ ed.). Thousand Oaks, CA: Sage.

Russell, G. M., \& Kelly, N. H. (2002, September). Research as Interacting Dialogic Processes: Implications for Reflexivity. In Forum: Qualitative Social Research (Vol. 3, No. 3).

Schmidt, R., \& Savage, W. (1992). Challenge, skill, and motivation. Pasaa, 22, 14-28.

Self-Determination Theory. (2015) Retrieved from http://www.selfdeterminationtheory.org/theory/

Self-Determination Theory. (2015) Retrieved from http://www.selfdeterminationtheory.org/theory/

Silverman, D. (1993) Interpreting Qualitative Data: Methods for Analyzing Talk, Text and Interaction. Sage, London.

Skehan, P. (1991). Individual differences in second language learning. Studies in second language acquisition, 13(02), 275-298.

“soka gakkai.” Merriam-Webster. (2015). In Merriam-Webster.com.Retrieved April 13, 2015, from http://www.merriam-webster.com/dictionary/soka\%20gakkai

Strauss, A. L., \& Corbin, J. M. (1990). Basics of qualitative research (Vol. 15). Newbury Park, CA: Sage.

Strauss, A. L., \& Corbin, J. M. (1998). Basics of qualitative research: Techniques and procedures for developing grounded theory. Thousand Oaks: Sage Publications.

Suzuki, M. (2011). Ideal L2 Selves of Japanese English Learners at Different Motivational Level.

Tae-Young Kim. "The L2 Motivational Self System of Korean EFL Students: Crossgrade Survey Analysis" English Teaching 67.1 (2012): 29-56.

“The hierarchical relationships of senpai and kohai in Japanese companies.” Tsunagu Japan (2014). (2015, October 12). Retrieved from https://www.tsunagujapan.com/the-hierarchical-relationships-of-senpai-andkohai-in-japanese-companies/ 
The Japan Foundation (2006). The Japanese Language Program Coordinators' Meeting by the Japan Foundation, Los Angeles (February, 2006). Retrieved from: http://www.jflalc.org/download/education/JPLCMeeting.pdf

The Japan Foundation. (2008, June) Revision of the Japanese-Language Proficiency Test: Second Progress Report. Japan Foundation. Retrieved from:www.jpf.org.uk/language/download/jlpt-prog-rep2-english.doc

The Japan Foundation (2009). Present Condition of Overseas Japanese-Language Education: Survey Report on Japanese-Language Education Abroad 2009 Summary. Retrieved from: http://www.jpf.go.jp/e/japanese/survey/result/survey09.html

The Japan Foundation (2012). Present Condition of Overseas Japanese-Language Education: Survey Report on Japanese-Language Education Abroad 2012 Summary. Retrieved from: http://www.jpf.go.jp/e/japanese/new/1208/08_01.html

The Japanese Ministry of Health, Labor and Welfare (2010) Retrieved from: http://www.mhlw.go.jp/seisaku/2010/02/02.html

Tosaku, Y. (2009). Issues confronting Japanese-language education in the United States. Breeze, 37. Retrieved from: http://www.jflalc.org/pub-breeze37.html

Tsutsui, M. (2010). Japanese for technical and business professions at the University of Washington: curricula and syllabi. Occasional Papers, 10. Retrieved from: http://www.aatj.org/publications/occasionalpapers/OccPapers_10.pdf

U.S. Department of Education. (2006, October). \$12.9 million in grants awarded for Critical foreign language instruction. U.S. Department of Education. Retrieved from: http://www2.ed.gov/news/pressreleases/2006/10/10132006a.html

"Weekly Shonen Jump.” The Free Dictionary (2003-2015). (2015, October 12). Retrieved from http://encyclopedia.thefreedictionary.com/Weekly+Sh\%C3\%B4nen+Jump

Dörnyei, Z., \& Schmidt, R. (Eds.). (2001). Motivation and second language acquisition (Vol. 23). Natl Foreign Lg Resource Ctr.

Zimmermann, K. (2015). What is culture? Retrieved from http://m.livescience.com/21478-what-is-culture-definition-of-culture.html

小泉令三, \& 松尾馨. (1993). A longitudinal study of attitudes and motivation in learning English among Japanese seventh-grade students. Japanese Psychological Research, 35(1), 1-11. 


\section{APPENDICES}




\section{Appendix A}

\section{In-Depth Semi-Structured Individual Interview Protocol}

\section{Preparation}

I will send an e-mail to all the instructors who will be teaching JPN 1130 (Beginner's Japanese) in fall semester of 2014 by 8/10/2014. In search of twelve possible interview participants, this e-mail will explain what exactly I would like them to do in their first class on the first day of fall semester, 8/25/2014. I will make a copy of the same instructions and also the inquiry form asking students if they would be willing to participate in the study and providing me with their contact information so that I can reach them at a later time. The instructions to the instructors and the copies of the inquiry form for all students in each class will be placed in the instructors' mail boxes before $8 / 15 / 2014$. Inquiry forms will be distributed by the instructors towards the end of the first class on $8 / 25 / 2014$.

Participants will sign a written consent form before the recorded interview starts. At the beginning of the interview, detailed explanations about their participation in the study will be provided such as (a) their participation is completely voluntary (b) they have the right to withdraw from the study at any time without any penalty (c) their personal information and information provided during the interviews are confidential (d) all related materials included notes that I will take during the interviews will be securely stored in my personal computer which requires a password (e) information contained during the interviews may be used in materials to be made available to the general public (f) they will be anonymous and (g) the results of this study may be published. Same procedure will be done for Phase two.

\section{Research Question}

What are the non-Japanese undergraduate students of their reasons and purposes for taking a beginners' Japanese language course at Florida International University?

\section{Participants}

Twelve non-Japanese undergraduate students who are enrolled in a beginners' Japanese course in fall, 2014 at FIU.

Location 
Each participant will choose a quiet and comfortable place for the interview. If there is no request, I will offer my office at FIU.

\section{Conceptual Framework:}

\section{L2 Motivational Self System}

Definitions of ideal L2 self, ought-to L2 self and L2 learning experience (L2 Motivational Self System) were taken from Zoltan Dörnyei (2009). Interview questions below derived from Dörnyei’s article (2009) called “The L2 motivational self-system.” I will not ask all the questions below but prioritize them as the interview progresses, but I will touch on each dimension of the framework during the interview for inductive, comparative analysis that will be conducted later. In order to remain as open and adaptable as possible to the interviewee's nature and priorities, I will not be restricted to specific questions but be flexible in terms of how to approach towards different interview questions.

ideal L2-self

the ideal L2 self is based on the individual's aspirations and goals as a language learner the ideal L2 self refers to "the representation of the attributes that one would ideally like to possess (i.e. representation of hopes, aspirations, or wishes)” (Dörnyei, 2009, p.13).

the ideal L2 self is "a powerful motivator to learn the L2 because of the desire to reduce the discrepancy between our actual and ideal selves” (Dörnyei, 2009, p.29).

ought-to L2-self

the ought L2 self refers to "the representation of attributes that one believes one ought to possess (i.e. representation of someone else's sense of duties, obligations or moral responsibilities) and which therefore may bear little resemblance to one's own desires or wishes.” (Dörnyei, 2009, p.1)

the ought L2 self concerns "the attributes that one believes one ought to possess to meet expectations and to avoid possible negative outcomes. This dimension corresponds to the more extrinsic (i.e. less internalized) types of instrumental motives” (Dörnyei, 2009, p.13).

\section{L2 learning experience}

L2 learning experience concerns situated, 'executive' motives related to the immediate learning environment and experience (e.g. the impact of the teacher, the curriculum, the 
peer group, the experience of success). This component is conceptualised at a different level from the two self-guides and future research will hopefully elaborate on the selfaspects of this bottom-up process (Dörnyei, 2009, p.29).

\section{Time line (One-hour total)}

5 minutes - introduction and the warm-up

15 minutes - (a)

15minutes - (b)

15 minutes - (c)

10 minutes - summarizing

This is a rough estimate of the interview just to make sure that each dimension of the conceptual framework will be discussed during the interview. 


\section{Phase I (Beginning of fall, 2014)}

\section{Background Information}

Please introduce yourself and tell me your background information such as what program and which year of study you are in at FIU and etc.

Please describe your family background in terms of language(s) that you were surrounded by.

\section{Main Question}

What are the reasons and purposes of taking a Japanese language class at FIU?

\section{Questions Based on (a) L2 ideal-self}

1. Describe your purposes and purposes for studying Japanese language at FIU?

2. Describe your aspirations for studying Japanese language at FIU.

3. Describe your intended outcome of the course.

4. What is your expected Japanese proficiency?

5. How do you think it will make you feel speaking in Japanese in/out of class? Describe how it will look like.

6. How do you imagine yourself after the completion of this course as a language learner? In what way(s) do you think this course will help you get there?

7. In what way(s) would you like to become similar to the people who speak Japanese?

8. Describe yourself as successful user of Japanese in the future.

(How do you imagine yourself using Japanese language in the future? Describe your future in terms of Japanese language such as job that you might get involved with, who you are speaking Japanese to, how well you are using Japanese and where you may reside and etc.)

9. Describe how it will be like if you will not acquire the language as you expected, and what will it cost you? How will it look like.

10. In what way(s) do you think Japanese language learning will contribute to you? How will it look like?

11. Do you have specific identity when you learn or use Japanese language? Does it reflect how and who you are? Describe how it will look like. 


\section{Questions Based on (b) ought-to L2 self}

1. Describe what your parents/friends will think of you taking Japanese language? Describe what you think of their expectations are.

2. Describe what your parents/friends/teachers think of your sense of duties, obligations or moral responsibilities as a language learner taking Japanese at FIU.

3. How do you think your parents/teachers/friends think you will do in this class? How will it look like to them if you succeed or fail, how will it make you feel?

4. Describe the attributes that you believe one ought to possess (sense of duties, obligations or moral responsibilities) to get the results you want from learning. Describe how it will look like.

5. Describe what kind of attributes you think you will need to achieve the result you want in this course as a language learner, how will it look like.

6. How do you think you will reach your goal as a Japanese language learner and what will you do to avoid getting different results (i.e. failure)?

7. Describe your commitment to learning Japanese at FIU. How does it look like and what it's involved?

8. Describe the person whom you believe you ought to be to get the results you want as a language learner.

9. In terms of language learning, describe the person you don't want to be like.

\section{Questions Based on (c) L2 experience}

1. Describe your interest of studying Japanese at FIU.

2. When did you first have an interest in Japanese language and where?

3. Describe event(s), people (characters) or locations that affected you to start learning Japanese language at FIU.

4. Describe what is your most memorable (positive and negative) moment as a language learner. When did it happen? Where? How did it look like? How did it affect your reasons and purposes for learning the language at FIU?

5. What character/person/event have affected you most in your Japanese learning?

6. Describe the experiences that you expect to have in this class. How will it look like? How will it make you feel?

7. Describe in what way(s) your lessons will help you being a Japanese learner.

8. Among the four areas (listening, speaking, reading and writing), what is the most important area for you? In what way(s)?

9. Describe your ideal classroom environment. 
(How do you expect to feel about your teachers?)

(How do you expect to feel about your classmates?)

(How do you expect they (teachers and classmates) will help you to learn Japanese?)

10. Describe what kind of Japanese language related activities do you engage in your spare time. In what way(s)?

11. What kind of tools do you think will serve you best in learning Japanese in/outside of classroom? Why do you use them? In what way they will help you? Please give examples.

\section{Phase II (End of fall, 2014)}

What are the reasons and purposes of a taking Japanese language class at FIU?

\section{Questions Based on (a) L2 ideal-self}

Add "now that you have completed this course...." when appropriate.

1. Describe your reasons and purposes for studying Japanese language at FIU.

2. Describe your aspirations of studying Japanese language at FIU.

3. Describe your intended outcome of the course.

4. What is your expected Japanese proficiency?

5. How do you think it will make you feel speaking in Japanese? Describe how it will look like.

6. How do you imagine yourself now that you have completed this course as a language learner? In what way(s) do you think this course needed to help you get there?

7. In what way(s) would you like to become similar to the people who speak Japanese?

8. Describe yourself as successful user of Japanese in the future.

(How do you imagine yourself using Japanese language in the future? Describe your future in terms of Japanese language such as job that you might get involved with, who you are speaking Japanese to, how well you are using Japanese and where you may reside and etc.)

9. Describe how it will be like if you will not acquire the language as you expected, and what will it cost you. How will it look like?

10. In what way(s) do you think Japanese language learning will contribute to you? And how will it look like? 
11. Do you have specific identity when you learn or use Japanese language? Does it reflect how and who you are? Describe how it will look like.

\section{Questions Based on (b) ought-to L2 self}

1. Describe what your parents/friends will thought of you taking Japanese course at FIU. Describe what you think their expectations were and if you have not met their expectations.

2. Describe what your parents/friends/teachers think of your sense of duties, obligations or moral responsibilities as a language learner who took Japanese at FIU.

3. How do you think your parents/teachers/friends think you learned Japanese at FIU?

4. Describe the attributes that you believe one ought to possess (sense of duties, obligations or moral responsibilities) to get the results you want from learning Japanese? Describe how will it look like.

5. Describe what kind of attributes you think you will need to achieve the result you want as a language learner at FIU, how will it look like.

6. How do you think you will reach your goal as a Japanese language learner at FIU and what will you do to avoid getting different results (i.e. failure)?

7. Describe your commitment to learning Japanese at FIU? How does it look like and what it is involved.

8. Describe the person whom you believe you ought to be to get the results you want as a language learner at FIU.

9. In terms of language learning at FIU, describe the person you don't want to be like.

Questions Based on (c) L2 experience

1. Describe your interest of studying Japanese at FIU.

2. Describe what event(s) affected you to start learning Japanese language and why at FIU.

3. What is your most memorable (positive and negative) at FIU? When did it happen? Please describe.

4. What character/person/event have affected you most in your Japanese learning?

5. Describe your ideal classroom environment.

(How do you expect to feel about your teachers?)

(How do you expect to feel about your classmates?) 
(How do you expect they (teachers and classmates) will help you to learn Japanese?)

6. Describe what kind of Japanese language related activities do you engage in your spare time. In what way(s)?

7. What kind of tools do you think will serve you best in learning Japanese in and outside of classroom? Why and how do you use them? In what way they will help you? Please give examples.

\section{Inquirer Leads for Interview Questions:}

- When you say _ _ what does that mean to you?

- O Ok you said _ c c c _ you explain that a little more?

- Can you describe a situation where you have used that or felt that___ ?

- Think about_, describe

- You mentioned ___ How does that compare to___ ?

- $\quad$ How do you think it will make you feel? How did that make you feel?

- What will you think about that? What did you think about that?

- How will ___ respond? How did ___ respond?

- How will that make you feel? How did that make you feel?

- $\quad$ Do you remember what you were feeling at the time?

- What will you do about that feeling? What did you do about that feeling?

- What will this feeling/experience mean to you? What did this feeling/experience meant to you?

- What thoughts were you having ?

- What kind of image were you projecting? Is this the type of image you wanted to project?

- Can you recall ? 


\section{Appendix B}

\section{E-mail sent to Instructors}

Dear Instructors of JPN1130 (Fall, 2014)

In seeking interview participants for my dissertation which explores reasons and purposes of non-Japanese undergraduate students for taking a beginners' Japanese language course at Florida International University, I have created a simple permission form.

I would appreciate it if you would distribute this form to your students during the last 10 minutes of your first day of class on August 25, 2014. Please read the instructions below when you distribute the form. You will be receiving copies of the form in your mail box for all the students in your class.

Once the students have completed the form, please leave them in my mailbox, located on the 4th floor of the Modern Languages Department.

I thank you in advance for helping me find possible participants for my study. If you have any questions, please do not hesitate to contact me. Asuka Mashav (Mashava@fiu.edu, 305-348-6516).

Please read the following instructions to your students on August 25, 2014, before you

distribute an inquiry form to your students.

"There is an instructor/doctoral student who is working on a dissertation to explore non-Japanese undergraduate students’ reasons and purposes for taking a beginners' Japanese language course at FIU. She is looking for possible participants who are willing to be interviewed for an hour during the first week of this semester and also at the end of this semester. This interview is completely voluntary, and any information you provide will be strictly confidential. Also, you will be anonymous if you wish. I will distribute a form now. It will ask you for your name and contact information, as well as your permission to participate in the study. If you are interested in participating, please fill out this form and give it back to me. The instructor will then contact you via e-mail and/or phone. If you are not willing to participate in the study, just check "no" on the form. Thank you very much for your time and cooperation.” 


\section{Appendix C}

\section{Form to Find Possible Participants}

$8 / 19 / 2014$

Dear Students

I am investigating reasons and purposes of non-Japanese undergraduate students who take beginners' Japanese language courses at Florida International University and I would like your participation to help me understand this research topic.

Your participation will involve one-hour interview sometime this week and another onehour interview at the end of this course. YOUR PARTICIPATION IS VOLUNTARY AND NOT RELATED IN ANY WAY TO YOUR GRADE IN THIS CLASS.

Yes, I will be willing to participate.

No, I will not.

$\underline{\text { Information on Possible Interview Participants }}$

Name

Gender

E-mail address

Phone number

If you answered yes, I will contact right away via e-mail/phone to set up an appointment with you. Thank you!

Asuka Mashav

Mashava@fiu.edu

305-348-6516 


\section{Appendix D}

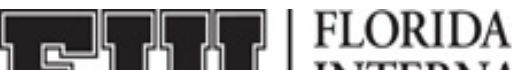 INTERNATIONAL UNIVERSITY}

\section{ADULT CONSENT TO PARTICIPATE IN A RESEARCH STUDY}

An Exploration of the Reasons and Purposes of Non-Japanese

Undergraduate Students for Taking a Beginners’ Japanese Language Course

at Florida International University

\section{PURPOSE OF THE STUDY}

You are being asked to be in a research study. The purpose of this study is to explore the reasons and purposes of non-Japanese undergraduate students for taking a beginners' Japanese language course at Florida International University.

\section{NUMBER OF STUDY PARTICIPANTS}

If you decide to be in this study, you will be one of twelve people in this research study.

\section{DURATION OF THE STUDY}

Your participation will require one-hour interview during the first week of fall, 2014 semester and at the end of fall, 2014 semester.

\section{PROCEDURES}

If you agree to be in the study, we will ask you to do the following things:

2 one-hour semi-structured recorded interview sessions at the beginning and the end of fall, 2014 semester.

\section{RISKS AND/OR DISCOMFORTS}

The following risks may be associated with your participation in this study: First, there are no known risks for participating in this study; Second, a few interview questions may make you uncomfortable, but the participants do not have to answer particular questions and also free to withdraw from the study at any time without any penalty. 


\section{BENEFITS}

The following benefits may be associated with your participation in this study: to acknowledge the reason(s) and purpose(s) of taking a beginners' Japanese language course at Florida International University.

\section{ALTERNATIVES}

There are no known alternatives available to you other than not taking part in this study. However, any significant new findings developed during the course of the research which may relate to your willingness to continue participation will be provided to you.

\section{CONFIDENTIALITY}

The records of this study will be kept private and will be protected to the fullest extent provided by law. In any sort of report we might publish, we will not include any information that will make it possible to identify a subject. Research records will be stored securely and only the researcher team will have access to the records. However, your records may be reviewed for audit purposes by authorized University or other agents who will be bound by the same provisions of confidentiality.

\section{COMPENSATION \& COSTS}

You will not be responsible for any costs to participate in this study.

\section{RIGHT TO DECLINE OR WITHDRAW}

Your participation in this study is voluntary. You are free to participate in the study or withdraw your consent at any time during the study. Your withdrawal or lack of participation will not affect any benefits to which you are otherwise entitled. The investigator reserves the right to remove you without your consent at such time that they feel it is in the best interest.

\section{RESEARCHER CONTACT INFORMATION}

If you have any questions about the purpose, procedures, or any other issues relating to this research study you may contact Asuka Mashav at 11200 SW 8th St. DM481A Miami, FL 33199 (Florida International University), 305-348-6516, Mashava@fiu.edu.

\section{IRB CONTACT INFORMATION}

If you would like to talk with someone about your rights of being a subject in this research study or about ethical issues with this research study, you may contact the FIU Office of Research 
Integrity by phone at 305-348-2494 or by email at ori@fiu.edu.

\section{PARTICIPANT AGREEMENT}

I have read the information in this consent form and agree to participate in this study. I have had a chance to ask any questions I have about this study, and they have been answered for me. I understand that I will be given copy of this form for my records.

Signature of Participant

Printed Name of Participant
Date

Date 


\section{Appendix E}

\section{Consent Form for Interviews}

$\mathrm{I}$, agree to be interviewed for the research study entitled "An

exploration of reason(s) and purpose(s) of non-Japanese undergraduate students who choose to take beginners' Japanese language course” which will be produced by Asuka Haraguchi Mashav of Florida International University.

I certify that I have been told of the confidentiality of information collected for this research study and the anonymity of my participations. I have been advised that I am free to withdraw my consent and to discontinue participation in the research study or activity at any time without prejudice.

I agree to participate in two interviews, one at the beginning of the fall semester, 2014 and after the fall semester, 2014. I also understand the following. (a) their participation is completely voluntary (b) they have the right to withdraw from the study at any time without any penalty (c) their personal information and information provided during the interviews are confidential (d) all related materials included notes that I will take during the interviews will be securely stored in my personal computer which requires a password (e) information contained during the interviews may be used in materials to be made available to the general public (f) they will be anonymous if they wish (g) the results of this study may be published.

I agree that any information obtained from this research study may be used in any way through best for this study.

Date

Signature of Interviewee

\section{Contact information}

If you have any questions or concerns about this study, please contact Asuka Haraguchi Mashav at 305-348-6516.

A copy of this consent form should be given to you. 


\section{Appendix F}

General Overview of Japanese and Chinese Related Information (as of 2015)

\begin{tabular}{|c|c|c|}
\hline & Japanese & Chinese \\
\hline $\begin{array}{c}\text { Language } \\
\text { Proficiency Test }\end{array}$ & $\begin{array}{l}\text { JLPT (Japanese Language } \\
\text { Proficiency Test) }\end{array}$ & $\begin{array}{l}\text { HSK (Hanyu Shuiping Kaoshi) } \\
\text { FIU (Currently Testing Site) }\end{array}$ \\
\hline $\begin{array}{c}\text { Local } \\
\text { Language School }\end{array}$ & $\begin{array}{l}\text { Hoshuko in Miami } \\
\text { (Japanese school for } \\
\text { Japanese Natives) } \\
\end{array}$ & $\begin{array}{l}\text { Contemporary Chinese School } \\
\text { at Coral Gables H.S in Miami }\end{array}$ \\
\hline $\begin{array}{c}\text { Local } \\
\text { Professional } \\
\text { Language } \\
\text { Organization }\end{array}$ & $\begin{array}{c}\text { AFTJ } \\
\text { (Association for Florida } \\
\text { Teachers of Japanese) }\end{array}$ & $\begin{array}{c}\text { CLTA-FL } \\
\text { (Chinese Language Teachers } \\
\text { Association - Florida) } \\
\text { FCTA (Florida Chinese } \\
\text { Teachers' Association) }\end{array}$ \\
\hline $\begin{array}{l}\text { Main National } \\
\text { Professional } \\
\text { Language } \\
\text { Organization }\end{array}$ & $\begin{array}{c}\text { AATJ } \\
\text { (American Association of } \\
\text { Teachers of Japanese) } \\
\text { NCLTJ } \\
\text { (National Council of } \\
\text { Japanese Language } \\
\text { Teachers) }\end{array}$ & $\begin{array}{c}\text { CLTA } \\
\text { CSAUS (Chinese School } \\
\text { Association in the United } \\
\text { States) } \\
\text { CLASS (Chinese Language } \\
\text { Association of Secondary- } \\
\text { Elementary schools) }\end{array}$ \\
\hline $\begin{array}{c}\text { Main Government } \\
\text { Organization }\end{array}$ & Japan Foundation & HanBan \\
\hline Closest Consulate & Miami & Houston \\
\hline Key Cultural Sites & Morikami Museum & \\
\hline $\begin{array}{l}\text { Local } \\
\text { Cultural Events } \\
\text { Sites }\end{array}$ & $\begin{array}{l}\text { Morikami Museum } \\
\text { Florida Int’l University }\end{array}$ & $\begin{array}{c}\text { Miami Dade College } \\
\text { (New Year's Day) } \\
\text { Confucius Institute at Miami } \\
\text { Dade College in Miami } \\
\text { Florida Int'l University }\end{array}$ \\
\hline $\begin{array}{l}\text { Community- } \\
\text { Based Language } \\
\text { Classes }\end{array}$ & $\begin{array}{l}\text { Miami Dade College } \\
\text { Morikami Museum } \\
\text { University of Miami }\end{array}$ & $\begin{array}{c}\text { University of Miami } \\
\text { Miami Dade College } \\
\text { Coral Springs Chinese Cultural } \\
\text { Association }\end{array}$ \\
\hline
\end{tabular}




\section{Appendix G}

\section{Analysis of Background in Asian and Japanese Program at FIU}

The following seem to be factors related to growth of Asian/Japanese Program at FIU.

- There are no universities that focus on Asian Studies in South Florida. As other Asian Studies programs in Florida weaken, more students will come to the FIU Japanese program from other parts of Florida.

- FIU has several Asia and Japan-related Clubs and the network among those clubs are productive through their faculty advisors who belong to Asian Studies Program or MOL.

- FIU has 2 full-time Japanese language instructors and now 1 associate professor in literature. All instructors including 3 adjunct instructors who are members of AFTJ (Association of Florida Teachers of Japanese), which helps for articulation between the K-12 and university levels of Japanese language study.

- FIU offers 3 semester exchange programs and 1 summer study abroad which all are popular among students. One more summer study abroad program may be added near future because of demand.

- Key organizations such as the Japanese Consulate, Morikami Museum and Garden, and Miami Hoshuko (Japanese school for Japanese natives), which all contribute to a Japanese presence in the community and relatively near FIU, also attract students to FIU's Asian Studies program and Japanese language courses.

- FIU Asian Studies Program along with MOL have various cultural and academic events on and off campus and has become centralized institutions for networking with various organizations in the community.

- Active local teachers’ professional association (articulation for K-16)

The following are met for Asian Studies/Japanese Program at FIU and its community for success so far as Lin’s (2009) exact chart that was presented previously shows.

- Full-time instructors

- Dedicated instructors and communication among them in all school levels

- Communication among instructors in the area in all school levels

- The interests and involvement of the department and program chair 
- Availability and financial support for professional development

- Implementation of classes in K-12

- Visibility through academic and cultural events on and off campus

- Governmental support

- Funding for various projects and hiring

- A centralized academic unit which can create a network in the community 
VITA

ASUKA HARAGUCHI MASHAV

Born, Kurume, Fukuoka, Japan

\section{EDUCATION AND EXPERIENCE}

1990

One-year exchange student

Cocalico High School, Denver, Pennsylvania

1995

B.A. in English

Kyoto University of Foreign Studies, Kyoto, Japan

1997

M.A. in Education

Millersville University of Pennsylvania, Millersville, Pennsylvania International Ambassador: Rotary International

1999

M.S. in Int'l/Intercultural Development Education

Educational Foundations and Policy Studies Department

Florida State University, Tallahassee, Florida

2000

Lecturer of Japanese Language

Arts and Sciences Department and Humanities Department

Barry University, Miami, Florida

2000- 2011

Instructor of Japanese Language Asian Studies Program, Modern Languages Department

Florida International University, Miami, Florida

2011- Present

Japanese Program Coordinator/Senior Instructor

Modern Languages Department

Assistant Director of Languages Programs

Asian Studies Program

Florida International University, Miami, Florida 